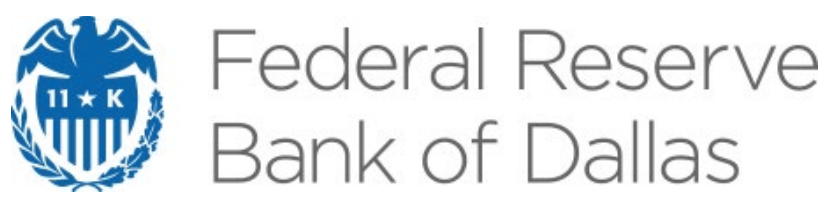

\title{
In No Uncertain Terms: The Effect of Uncertainty on Credit Frictions and Monetary Policy
}

Nathan S. Balke, Enrique Martínez-García and Zheng Zeng 


\title{
In No Uncertain Terms: The Effect of Uncertainty on Credit Frictions and Monetary Policy ${ }^{*}$
}

\author{
Nathan S. Balke ${ }^{\dagger}$, Enrique Martínez-García ${ }^{\ddagger}$ and Zheng Zeng ${ }^{\S}$ \\ June 2017 \\ Revised: January 21, 2021
}

\begin{abstract}
We examine the interaction of uncertainty and credit frictions in a New Keynesian framework. The model considers credit frictions arising from costly-state verification in the provision of loans to fund the acquisition of capital by entrepreneurs and includes three types of time-varying stochastic volatility shocks related to monetary policy uncertainty, financial risk (micro-uncertainty), and macro-uncertainty. Key parameters are estimated by the Simulated Method of Moments using U.S. data from 1984:Q1 until 2014:Q4. We find: 1 . Micro-uncertainty has first-order effects that are significantly larger than the effects of macro-uncertainty and monetary policy uncertainty. 2. Poor credit conditions exacerbate the economic drag from micro-uncertainty shocks, amplify the effects of monetary policy shocks, and mitigate the impact of TFP shocks. 3. A degree of asymmetry and non-scalability appears in response to monetary policy shocks, dependent on the degree of nominal rigidities and initial conditions. 4. Monetary policy uncertainty accounts for about one-third of the business cycle volatility largely by affecting the size of monetary policy shocks.
\end{abstract}

JEL Classification: E32, E44, D8, C32.

Keywords: Financial Accelerator, Stochastic Volatility, Monetary Policy Transmission, Nominal Rigidities, Perturbation Methods.

\footnotetext{
*We thank the editor and two anonymous referees for their many helpful suggestions. This document has also greatly benefited from valuable feedback provided by Francesco Bianchi, Andrés Blanco, Nicholas A. Bloom, Claudio Borio, Benjamin Born, William A. Brock, James Bullard, Dario Caldara, Lawrence J. Christiano, Olivier Coibion, Mario J. Crucini, Pablo Cuba-Borda, Michael B. Devereux, Martin Eichenbaum, Charles Engel, Emilio Fernández-Corugedo, Andrew Filardo, Timothy S. Fuerst, Fabio Ghironi, Marc P. Giannoni, Simon Gilchrist, Pablo A. Guerrón-Quintana, Joseph H. Haslag, Raju Huidrom, John Keating, Finn E. Kydland, Zheng Liu, Lilia Maliar, Rodolfo Manuelli, Antoine Martin, Leonardo Melosi, Marco del Negro, Filippo Occhino, Anna Orlik, Matthias O. Paustian, Giorgio E. Primiceri, Erwan Quintin, Barbara Rossi, Juan F. Rubío-Ramírez, Stephanie Schmitt-Grohe, Jae W. Sim, Eric Sims, Johannes Strobel, John B. Taylor, Stephen J. Terry, Martín Uribe, Víctor Valcárcel, Diego Vilán, Michael Weiss, Eric Van Wincoop, Egon Zakrajsek, and the many participants at the "Credit Market Frictions, Business Cycles, and Monetary Policy: A Research Conference in Honor of Charles Carlstrom and Timothy Fuerst" held at Notre Dame University (October 18-19, 2018). We acknowledge the excellent research assistance provided by Valerie Grossman. Earlier drafts circulated under the titles "Credit Uncertainty Cycles" and "Understanding the Aggregate Effects of Credit Frictions and Uncertainty." Additional results can be found at: https://doi.org/10.24149/gwp317suppr2. All remaining errors are ours alone. The views expressed here do not necessarily reflect those of the Federal Reserve Bank of Dallas or the Federal Reserve System.

${ }^{\dagger}$ Nathan S. Balke, Department of Economics, Southern Methodist University, Dallas, TX 75275. Phone: (214) 768-2693. Email: nbalke@smu.edu and Federal Reserve Bank of Dallas.

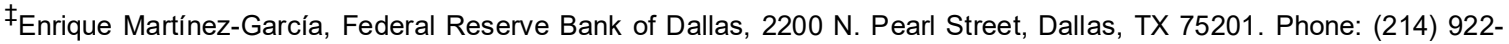
5262. Fax: (214) 922-5194. E-mail: emg.economics@gmail.com. Webpage: https://sites.google.com/view/emgeconomics.

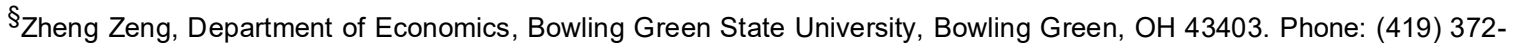
8397. E-mail: zzeng@bgsu.edu.
} 


\section{Introduction}

In the late 2000s, the U.S. experienced its longest recession in the post-World War II period. Credit market disruptions, unseen in the U.S. since the Great Depression, occurred while uncertainty heightened. The unique character of the 2007 - 09 Global Financial Crisis sparked a renewed interest in the role played by uncertainty and credit market frictions in propagating and prolonging economic downturns. In this paper, we provide a quantitative assessment of the extent to which uncertainty exacerbates credit frictions that can result in a "financial crunch" consistent with the U.S. experience. We also explore how worsening credit conditions during a financial crisis affect the transmission mechanism of monetary policy and condition the monetary policy responses. ${ }^{1}$

To do this, we estimate a medium-scale New Keynesian model where capital accumulation is subject to adjustment costs (real rigidities as in Hayashi (1982)) and financed through risky nominal loans. Credit frictions stem from information asymmetry between borrowers and lenders under limited liability and costly loan verification, as in Townsend (1979), Gale and Hellwig (1985), and Bernanke et al. (1999). These credit frictions result in agency costs from defaults that are passed to borrowers through credit spreads, increasing borrowing costs for entrepreneurs and restraining investment and economic activity. Similarly, collateral constraints tied to asset values can also amplify the downturn, to some extent. This financial accelerator mechanism has been articulated by, among others, Bernanke and Gertler (1989), Bernanke et al. (1996), Carlstrom and Fuerst (1997), Kiyotaki and Moore (1997), Bernanke et al. (1999), Kocherlakota (2000), Córdoba and Ripoll (2004), and Martínez-García (2014). ${ }^{2}$

Dorofeenko et al. (2008), Gilchrist et al. (2013), Christiano et al. (2014), an earlier working paper version of this article circulated as Balke et al. (2017a), and Cesa-Bianchi and Fernández-Corugedo (2018) have also shown that some second-moment shocks can have large, first-order impacts on economic activity even in general equilibrium when they are priced into credit spreads. This financial lever channel operating through credit spreads makes it plausible for second-moment shocks to originate (not just amplify) economic downturns.

The paper closest to ours in the literature is Cesa-Bianchi and Fernández-Corugedo (2018) which considers a setup with financial frictions and different forms of uncertainty similar to

\footnotetext{
${ }^{1}$ A recent take on the lessons learned from the 2007 - 09 Global Financial Crisis for the conduct of monetary policy during the COVID19 recession can be found in Coulter and Martínez-García (2020).

${ }^{2}$ For more discussion on the qualitative and quantitative effects of credit frictions on real economic activity, see e.g. Gerke et al. (2013) and Mendicino and Zhang (2018). Credit frictions also can influence the transmission mechanism of monetary policy as seen, e.g., in Carlstrom et al. (2010), Cohen-Cole and Martínez-García (2010), Lombardo and McAdam (2012), Dib et al. (2013), Gilchrist et al. (2013), Christiano et al. (2014), Paleka and Schwanebeck (2017), and de Blas and Malmierca (2020).
} 
ours. ${ }^{3}$ However, unlike Cesa-Bianchi and Fernández-Corugedo (2018) and the previous literature, we show that the importance of the financial lever channel (the interaction between credit frictions and certain forms of uncertainty) goes beyond the average first-order effects of financially-related uncertainty documented elsewhere. Our main novel contribution is the quantitative evidence we uncover of state-dependence, nonlinearities, and asymmetries affecting the propagation of shocks when financial conditions are poor (credit spreads are high). This implies that an economic downturn can be significantly more severe (becoming a "financial crunch") when financial risks are rising and financial conditions poor than when credit spreads are low and stable.

To show this, we quantitatively explore the financial lever channel in relation to three distinct forms of uncertainty: ${ }^{4}$

(i) Macro-uncertainty or aggregate uncertainty about the evolution of the economy brought about by time-varying stochastic volatility innovations in total factor productivity (TFP) (Alexopoulos and Cohen (2009), Bloom (2009), Bloom et al. (2018), Cesa-Bianchi and Fernández-Corugedo (2018));

(ii) Monetary policy uncertainty or time-varying stochastic volatility of the monetary policy shock (Fernández-Villaverde et al. (2010), Born and Pfeifer (2014));

(iii) Micro-uncertainty or financial risk arising from the time-varying dispersion of (uninsurable) idiosyncratic entrepreneurial productivity shocks (Dorofeenko et al. (2008), Gilchrist et al. (2013), Christiano et al. (2014), Cesa-Bianchi and Fernández-Corugedo (2018)).

Following in the footsteps of Born and Pfeifer (2014) and Basu and Bundick (2017), we pin down the structural parameters of the model using a combination of calibration and estimation based on the Simulated Method of Moments (SMM) targeting U.S. data covering the period from 1984:Q1 to 2014:Q4. To solve the model, we use a pruned third-order approximation to strike a reasonable balance between accuracy and tractability (on this point, see, e.g., Fernández-Villaverde and Rubio-Ramírez (2005) and Fernández-Villaverde and Rubio-Ramírez (2006)). From our analysis of the business cycle implications and generalized impulse responses of the estimated model, we draw five main conclusions:

First, consistent with Christiano et al. (2014) and Cesa-Bianchi and Fernández-Corugedo

\footnotetext{
${ }^{3}$ Cesa-Bianchi and Fernández-Corugedo (2018) cite the earlier working paper version of our work that circulated as Balke et al. (2017a) noting as well the connections and similarities that exist between the research that we both pursued independently.

${ }^{4}$ We represent time-varying uncertainty with stochastic volatility models similar to those of FernándezVillaverde (2010), Fernández-Villaverde et al. (2010), Fernández-Villaverde et al. (2011), Born and Pfeifer (2014), and Basu and Bundick (2017). Unlike what the existing literature does, though, we study meanpreserving stochastic volatility in order to isolate the effects of second-moment shocks from those of firstmoment shocks which could otherwise be confounded under log-normality.
} 
(2018), we find that the micro-uncertainty shock (a second-moment shock) has first-order effects of similar magnitude to first-moment shocks like TFP or monetary policy shocks.

Second, investment, consumption, hours worked, and inflation are unconditionally procyclical, while credit spreads are countercyclical (markedly so during the 2007 - 09 Global Financial Crisis) in the U.S. data. TFP shocks alone cannot explain these patterns of comovement. ${ }^{5}$ In turn, a positive micro-uncertainty shock (an increase in financial risk), similar to what is expected from a positive (contractionary) monetary policy shock, leads to a decline in investment, consumption, hours worked, and inflation, and to a widening of credit spreads all of which contributes to account for the unconditional cyclical patterns found in the U.S.

Third, we find that exogenous micro-uncertainty is a major source of exogenous business cycle fluctuations and the main driver of credit spread fluctuations in the U.S. as it impacts the probability of default priced into the credit spreads. The endogenous feedback from economic conditions to credit conditions depends on what happens with the aggregate leverage of entrepreneurs and, consistent with the results of Levin et al. (2004), our evidence suggests those feedback effects are only modest in size. Hence, we observe that TFP and monetary shocks, whether to the level (first-moment) or to the uncertainty (second-moment), do not have large impact on credit risk spreads.

Fourth, monetary policy uncertainty shocks, on average, have effects on real variables an order of magnitude larger than macro-uncertainty shocks but still smaller than microuncertainty shocks. However, macro- and monetary policy uncertainty affect the size of TFP and particularly of monetary policy shocks. In that sense, time-varying uncertainty becomes an important amplification factor of the business cycle fluctuations caused by TFP shocks and specially by monetary policy shocks. In fact, keeping monetary policy uncertainty stable at its unconditional variance could lower aggregate output volatility in the U.S. by one-third.

Finally, we show that the impact of shocks on economic activity is path-dependent. Large initial credit spreads (generally the result of heightened micro-uncertainty) tend to dampen somewhat the TFP shocks' impact on output. However, if spreads are already wide, the effect of micro-uncertainty shocks on output is nearly $40 \%$ larger on impact than when spreads are narrow. This suggests that when credit conditions are deteriorating (widening spreads), additional micro-uncertainty shocks disproportionately worsen the downturn.

Furthermore, we show an economically-significant degree of asymmetry and non-scalability in the propagation of monetary policy shocks. On average, a two-standard-deviation negative (expansionary) monetary innovation boosts output on impact by about 2.16 times as

\footnotetext{
${ }^{5} \mathrm{~A}$ positive TFP shock boosts output and investment, lowers inflation, and allows households to consume more while cutting hours worked. Credit spreads are procyclical in this case but small in magnitude.
} 
much as a one-standard innovation does while a two-standard-deviation positive (contractionary) monetary innovation lowers output only about 1.85 times as much as a one-standard innovation would. When credit spreads are already wide, the effect of a contractionary (onestandard-deviation) monetary policy shock is nearly $20 \%$ larger than when spreads are low. This showcases how the monetary policy shock transmission mechanism depends on the degree of nominal rigidities in the model, but also on the nonlinearities that arise with the interaction between credit frictions and micro-uncertainty.

The remainder of the paper proceeds as follows: Section 2 describes our model with credit market imperfections and stochastic volatility. Section 3 discusses the third-order approximation of the model solution and the SMM strategy we employ to estimate the model's key structural parameters. Section 4 presents our nonlinear impulse response analysis and the business cycle implications of uncertainty. It also highlights the main quantitative findings derived from our model. Section 5 concludes. A discussion of our solution strategy for the pruned third-order approximation and our novel recursive implementation of the mean-preserving correction to stochastic volatility can be found in the Appendix. ${ }^{6}$

\section{Credit Frictions and Uncertainty}

In this paper, we extend the benchmark New Keynesian business cycle model with nominal and real rigidities to incorporate: 1, a financial accelerator mechanism based on the costlystate verification framework of Bernanke et al. (1999), but with risky debt expressed in nominal terms; 2, shocks to the cross-sectional dispersion of the idiosyncratic productivity shocks (micro-uncertainty) which induce financial risk, and 3, time-varying uncertainty in TFP (macro-uncertainty) and monetary policy (policy uncertainty). This section describes the building blocks of the model.

\section{$2.1 \quad$ Households}

The economy is populated by a continuum of mass one of identical and infinitely-lived households. Preferences are defined over household consumption, $C_{t}$, and household hours worked,

\footnotetext{
${ }^{6}$ Additional details on the model solution and the simulation and estimation methods together with a rich set of supplementary results are available in Balke et al. (2017b).
} 
$H_{t}$, based on an additively separable specification with internal habits in consumption: ${ }^{7}$

$$
U \equiv \mathbb{E}_{0} \sum_{t=0}^{\infty} \beta^{t}\left\{\frac{\left(C_{t}-b C_{t-1}\right)^{1-\chi}}{1-\chi}-\kappa \frac{H_{t}^{1+\xi}}{1+\xi}\right\},
$$

where $\chi \geq 0$ is the inverse of the intertemporal elasticity of substitution, $0 \leq b \leq 1$ the internal habit persistence, $\xi \geq 0$ the inverse of the Frisch elasticity of labor supply, $\kappa \geq 0$ the scaling of household labor disutility, and $0<\beta<1$ the intertemporal discount factor.

Households face the following nominal budget constraint:

$$
P_{t} C_{t}+B_{t} \leq W_{t} H_{t}+I_{t-1} B_{t-1}+D I V_{t}
$$

At time $t$, households consume an amount $C_{t}$ of the final good at a nominal price $P_{t}$ and save an amount $B_{t}$ through one-period nominal deposits offered by financial intermediaries. Households receive a gross nominal risk-free interest rate $I_{t-1}$ (known at time $t-1$ ) on their one-period nominal deposits maturing at time $t$ and earn income from supplying household hours $H_{t}$ at its competitive nominal wage rate $W_{t}$. Households own all financial and nonfinancial firms and receive nominal dividend payments $D I V_{t}$ from the profits or losses that retail firms generate (all other firms make zero profits in equilibrium).

Solving the households' optimization problem, we obtain that:

$$
\begin{aligned}
\frac{W_{t}}{P_{t}} & =\frac{\kappa H_{t}^{\xi}}{\Lambda_{t}}, \\
1 & =\beta \mathbb{E}_{t}\left[\left(\frac{\Lambda_{t+1}}{\Lambda_{t}}\right) \frac{P_{t}}{P_{t+1}} I_{t}\right],
\end{aligned}
$$

which are the labor supply and consumption-savings Euler equations, respectively. Here, $\Lambda_{t} \equiv\left(C_{t}-b C_{t-1}\right)^{-\chi}-b \beta \mathbb{E}_{t}\left[\left(C_{t+1}-b C_{t}\right)^{-\chi}\right]$ is the Lagrange multiplier on the households' budget constraint expressed in units of the final good. The households' equilibrium conditions also include the appropriate initial and no-Ponzi transversality conditions.

\footnotetext{
${ }^{7}$ We also consider Epstein-Zin preferences (as poposed by Epstein and Zin (1989)) as an additional robustness check to examine precautionary savings and wealth effects on the results. In work not reported in the paper due to space constraints, we have considered Jaimovich-Rebelo preferences as well - a special case of which is the GHH preferences with no income effects on labor used, for instance, by Cesa-Bianchi and Fernández-Corugedo (2018).
} 


\subsection{Financial Business Sector}

\subsubsection{Entrepreneurs (Borrowers)}

There is a continuum of entrepreneurs of unit mass with identical linear preferences on consumption, $C_{t}^{e}$, defined as follows:

$$
\mathbb{E}_{0} \sum_{t=0}^{\infty}(\gamma \beta)^{t} C_{t}^{e}
$$

where the parameter $0<\gamma<1$ scaling the intertemporal discount $\beta$ in (5) captures the probability of each entrepreneur surviving until next period. We assume full replacement of the fraction of entrepreneurs $1-\gamma$ who die to keep the mass of entrepreneurs constant and equal to one in each period. Entrepreneurs that die do not purchase capital, work, or sign new loan contracts, but instead consume their accumulated resources. The replacement entrepreneurs come with no resources, but earn income by inelastically supplying entrepreneurial hours worked (normalized to one), $H_{t}^{e}=1$. Entrepreneurs maximize their lifetime utility in (5) subject to a sequence of nominal budget constraints and a balance sheet identity.

At time $t-1$, entrepreneurs purchase the aggregate stock of physical capital that will be available for production at time $t, K_{t}$, at a price of $Q_{t-1}$ units of the final good per unit of physical capital. Entrepreneurs make this purchase from capital-good producers. The nominal expenditures on physical capital, $P_{t-1} Q_{t-1} K_{t}$, are financed with a combination of the entrepreneurs' accumulated nominal net worth (internal funds or equity), $N_{t-1}$, and external funding from financial intermediaries (via one-period loans), $L_{t-1}$. Hence, the entrepreneurs' balance sheet satisfies that $P_{t-1} Q_{t-1} K_{t}=L_{t-1}+N_{t-1}$. A linear technology transforms each unit of physical capital acquired at time $t-1$ into $\omega_{t-1}$ units of capital services at time $t$ where $\omega_{t-1}$ is a purely idiosyncratic productivity shock (i.i.d. across entrepreneurs) known to each entrepreneur at $t-1 .^{8}$

At time $t$, each entrepreneur rents $\omega_{t-1}$ units of the capital services to the wholesale producers and accrues a nominal capital income of $\omega_{t-1}\left[R_{t}^{w}+P_{t} \bar{Q}_{t}(1-\delta)\right]$ at time $t$ per unit of physical capital acquired at time $t-1$. This nominal capital income includes the earned competitive nominal rental rate on capital services, $R_{t}^{w}$, and the resale value in units of the final good, $\bar{Q}_{t}$, of the entrepreneurs' depreciated physical capital sold back to the capital-good producers. From here it follows that each entrepreneur's nominal return on

\footnotetext{
${ }^{8}$ While all entrepreneurs face the same physical capital purchasing decision problem ex ante and make identical choices to acquire and fund it at $t-1$, ex post differences emerge because each entrepreneur receives a different draw from $\omega_{t-1}$ which affects the nominal capital income each of them accrues at time $t$.
} 
physical capital is given by $\omega_{t-1} R_{t}^{e}$ where $R_{t}^{e}$ is the aggregate nominal return given as:

$$
\frac{R_{t}^{e}}{\Pi_{t}} \equiv\left[\frac{\frac{R_{t}^{w}}{P_{t}}+\bar{Q}_{t}(1-\delta)}{Q_{t-1}}\right]
$$

with $\Pi_{t} \equiv \frac{P_{t}}{P_{t-1}}$ being the gross inflation rate on final goods and $\delta$ the depreciation rate.

The idiosyncratic technology shock $\omega_{t}$ is log-normally distributed, i.e., $\ln \left(\omega_{t}\right) \sim N\left(\mu_{\omega, t}, \sigma_{\omega, t}^{2}\right)$. We denote the probability distribution function (pdf) and the cumulative distribution function (cdf) for $\omega_{t}$ as $\phi\left(\omega_{t} \mid \sigma_{\omega, t}\right)$ and $\Phi\left(\omega_{t} \mid \sigma_{\omega, t}\right)$, respectively. The conditional variance, $\sigma_{\omega, t}^{2}$, reflects the time $t$ dispersion of the cross-sectional distribution of $\omega_{t}$. We set $\sigma_{\omega, t} \equiv \sigma_{\omega} e^{\widehat{\sigma}_{\omega, t}}$ and model the time-varying log-conditional volatility $\widehat{\sigma}_{\omega, t} \equiv \ln \sigma_{\omega, t}-\ln \sigma_{\omega}$, which we refer to as the exogenous micro-uncertainty (or financial risk) shock, as follows:

$$
\widehat{\sigma}_{\omega, t}=v_{\omega} \widehat{\sigma}_{\omega, t-1}+\eta_{\omega} u_{\omega, t}
$$

where $u_{\omega, t}$ is i.i.d. $N(0,1)$ and uncorrelated with all other shock innovations. The parameter $0<v_{\omega}<1$ determines the persistence of $\widehat{\sigma}_{\omega, t}, \sigma_{\omega}>0$ the unconditional expected logvolatility, and $\eta_{\omega} \geq 0$ the standard deviation of the innovations. We set the time-varying conditional mean $\mu_{\omega, t}$ to be $\mu_{\omega, t}=-\frac{\sigma_{\omega, t}^{2}}{2}$ for the unconditional mean of $\omega_{t}$ to be meanpreserving such that $\mathbb{E}\left(\omega_{t}\right)=1$ for all $t$. Unlike elsewhere in the literature, using meanpreserving volatility shocks on micro-uncertainty and in all other stochastic volatility shocks allows us to more cleanly disentangle the effect of first-moment and second-moment shocks. ${ }^{9}$

Given this, by the law of large numbers, aggregating capital services across all entrepreneurs must be equal to the aggregate stock of physical capital each period. Each individual entrepreneur's nominal capital income at time $t$ is $\omega_{t-1}\left[R_{t}^{w}+P_{t} \bar{Q}_{t}(1-\delta)\right] K_{t}=$ $\omega_{t-1} R_{t}^{e} P_{t-1} Q_{t-1} K_{t}$. The idiosyncratic technology shock $\omega_{t-1}$ is realized after the $t-1$ nominal loan contract is signed and then costlessly observed by the individual entrepreneur. However, the entrepreneur's draw of $\omega_{t-1}$ is not observed by the financial intermediaries and verification (through monitoring) as well as enforcement of the terms of the loan are costly. A credit distortion arises here from the information asymmetry between entrepreneurs (borrowers)

\footnotetext{
${ }^{9}$ Few papers in the literature, notably Basu and Bundick (2017), have recognized that there is a firstmoment impact from stochastic volatility when the stochastic process is expressed in logs through a Jensen's inequality effect. To prevent that, Basu and Bundick (2017) use stochastic processes for the first- and second-moment shocks in levels instead of in logs. The disadvantage of doing so is that normally-distributed processes in levels can take negative values. Our approach keeps the stochastic processes in logs, ensures they are non-negative in levels, and also prevents second-moment shocks from having an impact on first-moments to cleanly isolate one from the other. See the Appendix and Balke et al. (2017b) for the technical details of our novel recursive approach to modeling mean-preserving stochastic volatility.
} 
and financial intermediaries (lenders).

At time $t$, default on a nominal loan occurs whenever the capital income earned is insufficient to cover the repayment of the loan, i.e., whenever:

$$
\omega_{t-1} R_{t}^{e} P_{t-1} Q_{t-1} K_{t} \leq R_{t}^{L} L_{t-1}
$$

where, $R_{t}^{L}$, is the nominal return required by the financial intermediaries on the risky nominal one-period loan, $L_{t-1}$. The return $R_{t}^{L}$ is defined implicitly in terms of a default threshold set on the idiosyncratic productivity shock, $\bar{\omega}_{t-1}$, which corresponds to the draw of $\omega_{t-1}$ that equates the nominal loan repayment owed to financial intermediaries with the nominal capital income accrued by the entrepreneur-i.e., $\bar{\omega}_{t-1}$ is such that $R_{t}^{L} L_{t-1}=\bar{\omega}_{t-1} R_{t}^{e} P_{t-1} Q_{t-1} K_{t}$.

If $\omega_{t-1}<\bar{\omega}_{t-1}$, the entrepreneur does default at time $t$. Under limited liability, the financial intermediaries can only recover the nominal capital income generated by the defaulting entrepreneur in that period, i.e., $\omega_{t-1}\left[R_{t}^{w}+P_{t} \bar{Q}_{t}(1-\delta)\right] K_{t}=\omega_{t-1} R_{t}^{e} P_{t-1} Q_{t-1} K_{t}$. The financial intermediaries always monitor the defaulting entrepreneurs to prevent misrepresentations of the nominal capital income but do so at a cost proportional to the amount recovered-i.e., at a cost $\mu \omega_{t-1} R_{t}^{e} P_{t-1} Q_{t-1} K_{t}$ where $0 \leq \mu<1$. The defaulting entrepreneur gets nothing, while the financial intermediaries retain $(1-\mu) \omega_{t-1} R_{t}^{e} P_{t-1} Q_{t-1} K_{t}$ after paying off the verification costs. If $\omega_{t-1} \geq \bar{\omega}_{t-1}$, the entrepreneur does not default at time $t$, pays $\bar{\omega}_{t-1} R_{t}^{e} P_{t-1} Q_{t-1} K_{t}$ to the financial intermediaries and accordingly keeps $\left(\omega_{t-1}-\bar{\omega}_{t-1}\right) R_{t}^{e} P_{t-1} Q_{t-1} K_{t}$.

The entrepreneurs' budget constraint can be expressed as follows:

$P_{t} C_{t}^{e}+P_{t} Q_{t} K_{t+1} \leq W_{t}^{e} H_{t}^{e}+\int_{\bar{\omega}_{t-1}}^{\infty}\left[\omega_{t-1} R_{t}^{e} P_{t-1} Q_{t-1} K_{t}-R_{t}^{L} L_{t-1}\right] \phi\left(\omega_{t-1} \mid \sigma_{\omega, t-1}\right) d \omega_{t-1}+L_{t}$.

Apart from nominal capital income net of borrowing costs, entrepreneurs get revenue from inelastically supplying one unit of entrepreneurial hours $\left(H_{t}^{e}=1\right)$ to wholesale producers at the competitive nominal wage, $W_{t}^{e}$, and also obtain nominal funds from new loans, $L_{t}$, secured from the financial intermediaries. ${ }^{10}$ These nominal resources are allocated to today's consumption, $C_{t}^{e}$, and for the acquisition of tomorrow's stock of physical capital, $K_{t+1}$.

\footnotetext{
${ }^{10} \mathrm{As}$ is the case in much of the literature, prior defaults on loans do not influence the terms of the new loans because they don't reveal any information about the idiosyncratic (i.i.d.) shocks at the heart of the informational asymmetry between borrowers and lenders. In other words, observed past defaults do not help predict future defaults for individual entrepreneurs.
} 


\subsubsection{Financial Intermediaries (Lenders)}

There is a continuum of mass one of identical, competitive financial intermediaries. At each time $t$, financial intermediaries offer one-period, fully-insured nominal deposits to households, $B_{t}$, which pay a gross nominal risk-free rate, $I_{t}$. These nominal deposits attract households' savings which are then transformed into the one-period nominal loans demanded by the entrepreneurs, $L_{t} \cdot{ }^{11}$ Financial contracts are written in nominal rather than real terms, unlike in Bernanke et al. (1999) and Martínez-García (2014).

The loan contracting problem reduces to optimally choosing the physical capital, $K_{t+1}$, and the default threshold, $\bar{\omega}_{t}$, that maximize the entrepreneurs' nominal capital returns net of borrowing costs, i.e.,

$$
P_{t} Q_{t} K_{t+1} \mathbb{E}_{t}\left[R_{t+1}^{e} f\left(\bar{\omega}_{t}, \sigma_{\omega, t}\right)\right]
$$

subject to the following participation constraint for the financial intermediaries:

$$
P_{t} Q_{t} K_{t+1} \mathbb{E}_{t}\left[R_{t+1}^{e} g\left(\bar{\omega}_{t}, \sigma_{\omega, t}\right)\right] \geq I_{t}\left[P_{t} Q_{t} K_{t+1}-N_{t}\right]
$$

where $f\left(\bar{\omega}_{t}, \sigma_{\omega, t}\right)>0$ and $g\left(\bar{\omega}_{t}, \sigma_{\omega, t}\right)>0$ denote the share of nominal capital income going to the entrepreneurs and the financial intermediaries, respectively. The participation constraint in (11) means that financial intermediaries can pool defaulting and non-defaulting loans but must be compensated, at the very least, with enough to repay the depositors (households) in full every period. In equilibrium, financial intermediaries break even in each period and make zero profits. Three conditions characterize the solution of the loan contract in (10) - (11).

First, an income sharing rule between entrepreneurs and financial intermediaries:

$$
f\left(\bar{\omega}_{t}, \sigma_{\omega, t}\right)+g\left(\bar{\omega}_{t}, \sigma_{\omega, t}\right)=1-\mu G\left(\bar{\omega}_{t}, \sigma_{\omega, t}\right)
$$

where $\mu G\left(\bar{\omega}_{t}, \sigma_{\omega, t}\right) \geq 0$ determines the fraction of nominal capital income lost due to monitoring costs (which is zero only if monitoring costs are zero, i.e., if $\mu=0$ ). ${ }^{12}$

\footnotetext{
${ }^{11}$ The financial intermediaries' balance sheet identity is given by $B_{t}=L_{t}$ (total deposits equal total loans).

${ }^{12}$ Section 3 in Balke et al. (2017b) provides a detailed derivation of the optimal one-period nominal loan contract in (10) - (11) and a formal derivation of the functions $f\left(\bar{\omega}_{t}, \sigma_{\omega, t}\right) \equiv \int_{\bar{\omega}_{t}}^{+\infty} \omega_{t} \phi\left(\omega_{t} \mid \sigma_{\omega, t}\right) d \omega_{t}-$ $\bar{\omega}_{t}\left(1-\Phi\left(\bar{\omega}_{t} \mid \sigma_{\omega, t}\right)\right), g\left(\bar{\omega}_{t}, \sigma_{\omega, t}\right)$, and $G\left(\bar{\omega}_{t}, \sigma_{\omega, t}\right) \equiv \int_{0}^{\bar{\omega}_{t}} \omega_{t} \phi\left(\omega_{t} \mid \sigma_{\omega, t}\right) d \omega_{t}$ under the log-normal distribution assumption imposed on $\omega_{t}$ (where $\phi\left(\omega_{t} \mid \sigma_{\omega, t}\right)$ and $\Phi\left(\omega_{t} \mid \sigma_{\omega, t}\right)$ denote the probability distribution function and the cumulative distribution function of the log-normal, respectively).
} 
Second, an optimal leverage condition:

$$
\frac{N_{t}}{P_{t} Q_{t} K_{t+1}}=\frac{f\left(\bar{\omega}_{t}, \sigma_{\omega, t}\right)}{f\left(\bar{\omega}_{t}, \sigma_{\omega, t}\right)+\lambda\left(\bar{\omega}_{t}, \sigma_{\omega, t}\right) g\left(\bar{\omega}_{t}, \sigma_{\omega, t}\right)},
$$

where $\lambda\left(\bar{\omega}_{t}, \sigma_{\omega, t}\right)$ is the Lagrange multiplier on the participation constraint in (11), i.e., $\lambda\left(\bar{\omega}_{t}, \sigma_{\omega, t}\right)$ is the shadow cost of enticing the financial intermediaries' participation. Equation (13) implies that the default threshold $\bar{\omega}_{t}$ depends on the micro-uncertainty shock, $\sigma_{\omega, t}$, and on the entrepreneurs' net-worth-to-asset ratio (or equity ratio), $\frac{N_{t}}{P_{t} Q_{t} K_{t+1}}$.

Finally, expected gross returns for the entrepreneurs must satisfy:

$$
\mathbb{E}_{t}\left[R_{t+1}^{e}\right]=s\left(\frac{N_{t}}{P_{t} Q_{t} K_{t+1}}, \sigma_{\omega, t}\right) I_{t}
$$

where the endogenous credit spread $s\left(\frac{N_{t}}{P_{t} Q_{t} K_{t+1}}, \sigma_{\omega, t}\right) \equiv \frac{\lambda\left(\overline{(}_{t}, \sigma_{\omega, t}\right)}{f\left(\bar{\omega}_{t}, \sigma_{\omega, t}\right)+\lambda\left(\bar{\omega}_{t}, \sigma_{\omega, t}\right) g\left(\bar{\omega}_{t}, \sigma_{\omega, t}\right)}>1$ is a function of micro-uncertainty, $\sigma_{\omega, t}$, and also of the entrepreneur's equity ratio, $\frac{N_{t}}{P_{t} Q_{t} K_{t+1}}$, whenever $\mu>0$ but is independent of both and equal to $s\left(\frac{N_{t}}{P_{t} Q_{t} K_{t+1}}, \sigma_{\omega, t}\right) \equiv 1$ if $\mu=0$.

As a result, the efficiency condition in (14) shows that capital demand must be lower when entrepreneurs are leveraged (the equity ratio is low) or when micro-uncertainty is high in this costly-state verification framework. That is because the expected nominal return on that last unit of capital being funded, $\mathbb{E}_{t}\left[R_{t+1}^{e}\right]$, must equate the external borrowing cost, $s\left(\frac{N_{t}}{P_{t} Q_{t} K_{t+1}}, \sigma_{\omega, t}\right) I_{t}$, and this borrowing cost is above the nominal risk-free rate, $I_{t} .{ }^{13}$

Entrepreneurial Net Worth Dynamics. The entrepreneurs' budget constraint in (9), which in equilibrium holds with equality, and the nominal loan contract's optimality condition in (13) pin down entrepreneurial nominal net worth, $N_{t}$, as:

$$
\begin{aligned}
N_{t} & =P_{t} Q_{t} K_{t+1}-L_{t}=W_{t}^{e} H_{t}^{e}+f\left(\bar{\omega}_{t-1}, \sigma_{\omega, t-1}\right) R_{t}^{e} P_{t-1} Q_{t-1} K_{t}-P_{t} C_{t}^{e} \\
& =W_{t}^{e} H_{t}^{e}+\left(f\left(\bar{\omega}_{t-1}, \sigma_{\omega, t-1}\right)+\lambda\left(\bar{\omega}_{t-1}, \sigma_{\omega, t-1}\right) g\left(\bar{\omega}_{t-1}, \sigma_{\omega, t-1}\right)\right) R_{t}^{e} N_{t-1}-P_{t} C_{t}^{e} .
\end{aligned}
$$

As described in (5), entrepreneurs are risk-neutral and die with probability $1-\gamma$ each period. Hence, entrepreneurs optimally postpone their consumption until death at which point they eat their accumulated net worth (but do not save or work). Entrepreneurs'

\footnotetext{
${ }^{13}$ As Gomes et al. (2003) note, the costly-state verification model of Bernanke et al. (1999) which we have adapted to the nominal case, unlike that of Carlstrom and Fuerst (1997), allows asset price movements (given by Tobin's q or $Q_{t}$ ) to interact with the financial frictions. This remains an important feature also in our setup as can be seen in equation (14).
} 
aggregate consumption, $C_{t}^{e}$, is given by:

$$
C_{t}^{e}=(1-\gamma)\left(f\left(\bar{\omega}_{t-1}, \sigma_{\omega, t-1}\right)+\lambda\left(\bar{\omega}_{t-1}, \sigma_{\omega, t-1}\right) g\left(\bar{\omega}_{t-1}, \sigma_{\omega, t-1}\right)\right) \frac{R_{t}^{e}}{\Pi_{t}}\left(\frac{N_{t-1}}{P_{t-1}}\right) .
$$

Dying entrepreneurs get replaced by the same fraction $1-\gamma$ of new entrepreneurs with no net worth of their own who, nonetheless, start earning income immediately by supplying entrepreneurial hours. Accordingly, it follows from equations (15) and (16) that the law of motion for nominal net worth, $N_{t}$, can be expressed as:

$$
\frac{N_{t}}{P_{t}}=\frac{W_{t}^{e}}{P_{t}} H_{t}^{e}+\left(\gamma\left(f\left(\bar{\omega}_{t-1}, \sigma_{\omega, t-1}\right)+\lambda\left(\bar{\omega}_{t-1}, \sigma_{\omega, t-1}\right) g\left(\bar{\omega}_{t-1}, \sigma_{\omega, t-1}\right)\right) \frac{R_{t}^{e}}{\Pi_{t}}\right) \frac{N_{t-1}}{P_{t-1}}
$$

where $H_{t}^{e}$ is inelastically supplied and normalized to one (as indicated before). That is, the entrepreneurs' aggregate net worth includes the per-period capital income that all surviving entrepreneurs accrue net of borrowing costs plus the entrepreneurial labor income of new and surviving entrepreneurs minus the aggregate consumption of the dying entrepreneurs.

\subsection{Non-Financial Business Sector}

\subsubsection{Capital-Goods Producers}

There is a continuum of mass one of identical capital-goods producers. As in Hayashi (1982), aggregate physical capital, $K_{t+1}$, evolves according to a law of motion with adjustment costs:

$$
K_{t+1}=(1-\delta) K_{t}+s_{k}\left(\frac{X_{t}}{K_{t}}\right) K_{t}
$$

where $X_{t}$ denotes units of the final good used for aggregate investment, $\frac{X_{t}}{K_{t}}$ is the investmentto-capital ratio, and $s_{k}\left(\frac{X_{t}}{K_{t}}\right)$ is the capital adjustment cost function. The production of physical capital is subject to technological constraints implicit in the adjustment cost specification proposed by Jermann (1998) and Boldrin et al. (2001), among others, i.e.,

$$
s_{k}\left(\frac{X_{t}}{K_{t}}\right) \equiv\left(\frac{\delta}{1-\frac{1}{\varphi_{k}}}\right)\left[\left(\frac{\frac{X_{t}}{K_{t}}}{\delta}\right)^{1-\frac{1}{\varphi_{k}}}-\frac{1}{\varphi_{k}}\right]
$$

where $\varphi_{k}>0$ is the degree of concavity of $s_{k}\left(\frac{X_{t}}{K_{t}}\right)$.

At time $t$, entrepreneurs purchase their physical capital for next period, $K_{t+1}$, at a price 
in units of the final good (or Tobin's q), $Q_{t}$, and sell today's depreciated stock of physical capital, $(1-\delta) K_{t}$, at a resale price of $\bar{Q}_{t}$ units of the final good. Capital producers purchase the depreciated physical capital back and acquire $X_{t}$ additional units of the final good for the production of $\left[s_{k}\left(\frac{X_{t}}{K_{t}}\right) \frac{K_{t}}{X_{t}}\right] X_{t}$ units of new physical capital. Given this, the nominal perperiod (static) profits of the capital-goods producers are $P_{t}\left(Q_{t} K_{t+1}-X_{t}-(1-\delta) \bar{Q}_{t} K_{t}\right)$. Solving the capital producers' static profit maximization problem to choose investment, $X_{t}$, subject to the constraints in (18) - (19), it follows that Tobin's q, $Q_{t}$, is given by:

$$
Q_{t}=\left[s_{k}^{\prime}\left(\frac{X_{t}}{K_{t}}\right)\right]^{-1}=\left(\frac{\frac{X_{t}}{K_{t}}}{\delta}\right)^{\frac{1}{\varphi_{k}}}
$$

Imposing that capital producers make zero profits in every period, i.e.,

$$
Q_{t} s_{k}\left(\frac{X_{t}}{K_{t}}\right)-\frac{X_{t}}{K_{t}}-(1-\delta)\left(\bar{Q}_{t}-Q_{t}\right)=0
$$

pins down $\bar{Q}_{t}$ as a function of Tobin's q, $Q_{t}$, and of the investment-to-capital ratio, $\frac{X_{t}}{K_{t}}$.

\subsubsection{Wholesale Firms}

There is a continuum of mass one of identical wholesale producers. Wholesale goods, $Y_{t}^{w}$, are produced with the following Cobb-Douglas technology:

$$
Y_{t}^{w}=e^{a_{t}-a}\left(K_{t}\right)^{\alpha}\left(H_{t}^{e}\right)^{\vartheta}\left(H_{t}\right)^{1-\alpha-\vartheta}
$$

combining hours from households, $H_{t}$, together with hours and rented capital services from entrepreneurs, $H_{t}^{e}$ and $K_{t}$ respectively. The capital share satisfies that $0 \leq \alpha<1$, the entrepreneurial labor share is $0<\vartheta<1$, and the household labor share is $0<1-\alpha-\vartheta<1$.

The stochastic process for aggregate productivity (TFP) in logs, $a_{t}$, in (22) is:

$$
a_{t}=\mu_{a, t}+\rho_{a}\left(a_{t-1}-\mu_{a, t-1}\right)+\sigma_{a, t} \varepsilon_{a, t}
$$

where $0<\rho_{a}<1$ denotes its persistence. The macro-uncertainty shock is defined as a shock to the stochastic volatility of TFP, $\sigma_{a, t} \equiv \sigma_{a} e^{\widehat{\sigma}_{a, t}}$, where $\sigma_{a}>0$, and

$$
\widehat{\sigma}_{a, t}=v_{a} \widehat{\sigma}_{a, t-1}+\eta_{a} u_{a, t}
$$

with $0<v_{a}<1$ and $\eta_{a} \geq 0$. The shock innovations $\varepsilon_{a, t}$ and $u_{a, t}$ are i.i.d. $N(0,1)$ 
and uncorrelated with each other and with all other shock innovations. The time-varying conditional mean, $\mu_{a, t}$, satisfies the recursion: $\mu_{a, t}=-\frac{\sigma_{a, t}^{2}}{2}+\rho_{a}^{2} \mu_{a, t-1}$ to ensure the stochastic volatility is mean-preserving. The unconditional mean is then expressed as $a \equiv-\frac{1}{2} \frac{\sigma_{a}^{2}}{1-\rho_{a}^{2}}$.

All wholesale producers operate in competitive markets and produce a homogeneous wholesale good sold at a nominal price, $P_{t}^{w}$. Hours worked from households and entrepreneurs are paid at their nominal wages, $W_{t}$ and $W_{t}^{e}$ respectively, and entrepreneurs' capital services at their nominal rental rate, $R_{t}^{w}$, generating per-period profits of $P_{t}^{w} Y_{t}^{w}-R_{t}^{w} K_{t}-W_{t} H_{t}-$ $W_{t}^{e} H_{t}^{e}$. Solving the (static) profit-maximization problem of the wholesale firms subject to (22) results in zero profits in equilibrium and the factors of production being remunerated at their marginal product, i.e.,

$$
\begin{aligned}
\frac{W_{t}}{P_{t}} & =(1-\alpha-\vartheta) \frac{P_{t}^{w r} Y_{t}^{w}}{H_{t}}, \\
\frac{W_{t}^{e}}{P_{t}} & =\vartheta \frac{P_{t}^{w r} Y_{t}^{w}}{H_{t}^{e}}, \\
\frac{R_{t}^{w}}{P_{t}} & =\alpha \frac{P_{t}^{w r} Y_{t}^{w}}{K_{t}},
\end{aligned}
$$

where $P_{t}^{w r} \equiv \frac{P_{t}^{w}}{P_{t}}$ is the price of wholesale goods, $P_{t}^{w}$, over the price of the final good, $P_{t}$.

\subsubsection{Final Goods and Retail Firms}

There is a continuum of differentiated retail varieties of mass one indexed $j \in[0,1]$. Final output $Y_{t}$ is bundled with a constant elasticity of substitution (CES) aggregator, $Y_{t} \equiv$ $\left[\int_{0}^{1} Y_{t}(j)^{\frac{\epsilon-1}{\epsilon}} d j\right]^{\frac{\epsilon}{\epsilon-1}}$, where $\epsilon>1$ is the elasticity of substitution across varieties and $Y_{t}(j)$ denotes the amount of each variety $j$. The corresponding final goods price, $P_{t}$, is given by $P_{t}=\left[\int_{0}^{1} P_{t}(j)^{1-\epsilon} d j\right]^{\frac{1}{1-\epsilon}}$, which is a function of the price of each variety $j, P_{t}(j)$. The optimal allocation of expenditure is:

$$
Y_{t}(j)=\left(\frac{P_{t}(j)}{P_{t}}\right)^{-\epsilon} Y_{t}, \forall j \in[0,1]
$$

which implies that retailers face a downward-sloping demand function.

Each variety $j$ is produced by a monopolistically competitive retail firm that chooses its price, $P_{t}(j)$, to maximize its expected discounted stream of nominal profits, i.e.,

$$
\mathbb{E}_{0} \sum_{t=0}^{\infty} \lambda_{t}\left[\left(P_{t}(j)-P_{t}^{w}\right) Y_{t}(j)-s_{p}\left(P_{t}(j), P_{t-1}(j)\right) P_{t} Y_{t}\right]
$$


subject to the demand function in (28) and the households' intertemporal marginal rate of substitution $\lambda_{t} \equiv \beta^{t} \frac{\Lambda_{t}}{\Lambda_{0}} \frac{P_{0}}{P_{t}}$ where $\Lambda_{t} \equiv\left(C_{t}-b C_{t-1}\right)^{-\chi}-b \beta \mathbb{E}_{t}\left[\left(C_{t+1}-b C_{t}\right)^{-\chi}\right]$. For each unit of its own variety sold, the retail firm needs to acquire a unit of the wholesale good at its nominal price, $P_{t}^{w}$. Nominal retail prices can change every period subject to Rotemberg (1982) adjustment costs, $s_{p}\left(P_{t}(j), P_{t-1}(j)\right)$, given by:

$$
s_{p}\left(P_{t}(j), P_{t-1}(j)\right)=\frac{\varphi_{p}}{2}\left(\frac{P_{t}(j)}{P_{t-1}(j)}-1\right)^{2}, \forall j \in[0,1]
$$

where $\varphi_{p} \geq 0$ scales the quadratic cost term. ${ }^{14}$

All retailers face the same optimization problem, choose the same optimal price $P_{t}(j)$, and have their profits or losses rebated lump-sum to the households. Thus, a symmetric equilibrium emerges where $P_{t}(j)=P_{t}$ and $Y_{t}(j)=Y_{t}$. It also follows in this case that $Y_{t}=Y_{t}^{w}$. The optimal price-setting equation that we obtain from the retailers' optimization problem can be expressed in this symmetric equilibrium as:

$$
\left[1-\varphi_{p}\left(\Pi_{t}-1\right) \Pi_{t}\right]+\varphi_{p} \beta \mathbb{E}_{t}\left[\left(\frac{\Lambda_{t+1}}{\Lambda_{t}}\right)\left(\left(\Pi_{t+1}-1\right) \Pi_{t+1} \frac{Y_{t+1}}{Y_{t}}\right)\right]=\left(1-P_{t}^{w r}\right) \epsilon
$$

where $\Pi_{t} \equiv \frac{P_{t}}{P_{t-1}}$ is the gross inflation rate and $P_{t}^{w r} \equiv \frac{P_{t}^{w}}{P_{t}}$ is the relative price of wholesale goods in units of the final good. In this context, $P_{t}^{w r}$ is interpreted as the retailers' real marginal cost or, conversely, $\frac{1}{P_{t}^{w r}}$ is the retailers' price markup over marginal costs.

Finally, the aggregate per-period resource constraint for final output is:

$$
Y_{t}=C_{t}+X_{t}+\frac{\varphi_{p}}{2}\left(\Pi_{t}-1\right)^{2} Y_{t}+\mu G\left(\bar{\omega}_{t-1}, \sigma_{\omega, t-1}\right) \frac{R_{t}^{e}}{\Pi_{t}} Q_{t-1} K_{t} .
$$

Equilibrium in the final goods market means the production of the final good, $Y_{t}$, in each period $t$ is allocated either to households' consumption, $C_{t}$, to capital-goods producers' investment, $X_{t}$, or gets lost due to price adjustment costs in the retail sector, $\frac{\varphi_{p}}{2}\left(\Pi_{t}-1\right)^{2} Y_{t}$, and agency costs in the financial intermediation sector, $\mu G\left(\bar{\omega}_{t-1}, \sigma_{\omega, t-1}\right) \frac{R_{t}^{e}}{\Pi_{t}} Q_{t-1} K_{t}$.

\subsection{Monetary Policy}

Ben-Haim et al. (2018) find that a simple Taylor (1993) rule outperforms more complicated rules that include credit spreads or a debt-to-GDP ratio as indicators of financial stability

\footnotetext{
${ }^{14}$ While Rotemberg (1982) adjustment costs is our benchmark, we also consider as a robustness how the model responds if instead we were to assume staggered price-setting à la Calvo (1983).
} 
whenever the central bank itself is uncertain about the parameters and shocks of the model. Given that, we retain the assumption that the monetary authority sets the nominal interest rate, $I_{t}$, following a Taylor (1993)-type monetary policy rule with inertia (in index form):

$$
\frac{I_{t}}{I}=\left(\frac{I_{t-1}}{I}\right)^{\rho_{i}}\left(\left(\frac{\Pi_{t}}{\Pi}\right)^{\psi_{\pi}}\left(\frac{Y_{t}}{Y_{t-1}}\right)^{\psi_{x}}\right)^{1-\rho_{i}} e^{m_{t}-m}
$$

where $I$ is the steady-state nominal interest rate, $\Pi_{t} \equiv \frac{P_{t}}{P_{t-1}}$ is the gross rate of inflation on final goods prices, $\Pi=1$ corresponds to the central bank's zero-net inflation target, and $\frac{Y_{t}}{Y_{t-1}}$ is the gross final output growth. ${ }^{15}$ The parameters $\psi_{\pi}>1$ and $\psi_{x}>0$ determine the sensitivity of the policy response to inflation deviations from target and to output growth fluctuations, respectively. The parameter $0 \leq \rho_{i}<1$ sets the monetary policy inertia.

The stochastic process for the monetary policy shock, $m_{t}$, can be written as:

$$
m_{t}=\mu_{m, t}+\rho_{m}\left(m_{t-1}-\mu_{m, t-1}\right)+\sigma_{m, t} \varepsilon_{m, t}
$$

where the shock persistence is given by $0<\rho_{m}<1$. The stochastic volatility of the monetary policy shocks (monetary policy uncertainty), $\sigma_{m, t} \equiv \sigma_{m} e^{\widehat{\sigma}_{m, t}}$, where $\sigma_{m}>0$, follows:

$$
\widehat{\sigma}_{m, t}=v_{m} \widehat{\sigma}_{m, t-1}+\eta_{m} u_{m, t}
$$

with $0<v_{m}<1$ and $\eta_{m} \geq 0$. The shock innovations $\varepsilon_{m, t}$ and $u_{m, t}$ are i.i.d. $N(0,1)$ and uncorrelated with each other and with all other innovations. The time-varying conditional mean, $\mu_{m, t}$, satisfies the recursion: $\mu_{m, t}=-\frac{\sigma_{m, t}^{2}}{2}+\rho_{m}^{2} \mu_{m, t-1}$ to ensure the stochastic volatility process is mean-preserving. The unconditional mean of the process $m$ is $m \equiv-\frac{1}{2} \frac{\sigma_{m}^{2}}{1-\rho_{m}^{2}}$.

\section{Estimating the Model}

As in Fernández-Villaverde et al. (2010), Fernández-Villaverde et al. (2011), and Born and Pfeifer (2014), we use a third-order perturbation with the control and state variables expressed in logs to locally approximate the model solution. ${ }^{16}$ Following Andreasen et al.

\footnotetext{
${ }^{15}$ Expressed in logs, equation (33) responds solely to inflation and output growth (the "growth gap"). Similar policy reaction functions are used by Fernández-Villaverde et al. (2010) and Basu and Bundick (2017)). We also considered an alternative specification where the policy rule responds to output in logdeviations from steady-state, but the results are not too dissimilar and are omitted from the paper.

${ }^{16}$ The log-linearizing approach discussed by Martínez-García (2018), among others, does not suffice here. This is because, even with a second-order approximation, stochastic volatility shocks - except micro-
} 
(2018), we prune the third-order approximation to avoid dynamic instability problems. ${ }^{17}$

Table 1 summarizes the calibration and estimation of the model parameters. The parameterized preference and technological parameters $(\beta, \chi, \xi, \alpha, \vartheta$, and $\delta)$ follow closely the values used by Bernanke et al. (1999) and Martínez-García (2014). We set the elasticity of substitution across varieties $\epsilon$ as in Basu (1996). The values for the parameters of the exogenous TFP shock process, the monetary policy shock process, and their corresponding stochastic volatilities $\left(\rho_{a}, \sigma_{a}, v_{a}, \eta_{a}, \rho_{m}, \sigma_{m}, v_{m}\right.$, and $\left.\eta_{m}\right)$ as well as the policy parameters $\left(\rho_{i}, \psi_{\pi}\right.$, and $\left.\psi_{x}\right)$ are based on the estimates from Born and Pfeifer (2014). Born and Pfeifer (2014) obtain those estimates directly from observed U.S. TFP and by fitting an inertial Taylor (1993) rule on U.S. short-term interest rates.

We estimate the values of the remaining nine structural parameters of the model $\left(\kappa, b, \varphi_{k}\right.$, $\varphi_{p}, \gamma, \mu, \sigma_{\omega}, v_{\omega}$, and $\left.\eta_{\omega}\right)$ with the Simulated Method of Moments (SMM) approach. That is, matching simulated moments from the model to values that are consistent with key empirical regularities found in the U.S. data together with a couple of conventional model parameter normalizations. Table 2 lists the moments we seek to match, their empirical values, and their data sources spanning the period from 1984:Q1 to 2014:Q4. Prior to computing any of the empirical moments reported in the paper, we extract the cyclical component of each series with a one-sided Hodrick-Prescott filter using a lambda of 1600 and a power of 2, except for the equity ratio and the nominal short-term interest rate that are demeaned instead. We apply the same filtering to the corresponding endogenous data simulated by the model to ensure the comparability between simulated and empirical moments.

Our SMM estimation strategy is a limited information technique that relies solely on a subset of key moments - not the full information in the data - in order to discipline the estimation of the structural parameters. The advantage of using a limited information method here is two-fold: first, we can use the same U.S. data to investigate how the model replicates other non-targeted moments for cross-validation purposes and, second, this approach tends to produce parameter estimates that are less sensitive to omitted variables or unmodeled features of the economy than estimates obtained with full-information techniques would.

The estimated parameter values for $\kappa, b, \varphi_{k}, \varphi_{p}, \gamma, \mu, \sigma_{\omega}, v_{\omega}$, and $\eta_{\omega}$ are chosen to minimize the weighted squared distance between nine key moments implied by the model and their counterparts in the data. The moments we choose to match are:

1. the mean of the credit spread $\left(400 \times \mathbb{E}_{t}\left(\ln \left(\frac{R_{t+1}^{e}}{I_{t}}\right)\right)\right)$,

uncertainty - would not enter into the decision rules in an interesting way.

${ }^{17}$ Further discussion of the pruned third-order approximation of the solution can be found in the Appendix. 
2. the mean of the equity ratio in levels $\left(100 \times \frac{N_{t}}{P_{t} Q_{t} K_{t+1}}\right)$,

3. the mean default probability $\left(100 \times \Phi_{t}^{\text {default }}\right.$ where $\left.\Phi_{t}^{\text {default }} \equiv \Phi\left(\bar{\omega}_{t} \mid \sigma_{\omega, t}\right)\right)$,

4. the mean household hours worked $\left(400 \times \ln \left(H_{t}\right)\right)$,

5. the variance of the credit spread $\left(400 \times \mathbb{E}_{t}\left(\ln \left(\frac{R_{t+1}^{e}}{I_{t}}\right)\right)\right)$,

6. the ratio of investment variance $\left(400 \times \ln \left(X_{t}\right)\right)$ to output variance $\left(400 \times \ln \left(Y_{t}\right)\right)$,

7. the first-order autocorrelation of the credit spread $\left(400 \times \mathbb{E}_{t}\left(\ln \left(\frac{R_{t+1}^{e}}{I_{t}}\right)\right)\right)$,

8. the first-order autocorrelation of nondurable consumption $\left(400 \times \ln \left(C_{t}\right)\right)$,

9. the first-order autocorrelation of inflation $\left(400 \times \ln \left(\Pi_{t}\right)\right)$.

Specifically, we minimize the following quadratic form:

$$
\min _{\kappa, b, \varphi_{k}, \varphi_{p}, \gamma, \mu, \sigma_{\omega}, v_{\omega}, \eta_{\omega}} \mathbf{M}^{\prime} \mathbf{W} \mathbf{M}
$$

where $\mathbf{W}$ is a weighting matrix and $\mathbf{M}$ is given by,

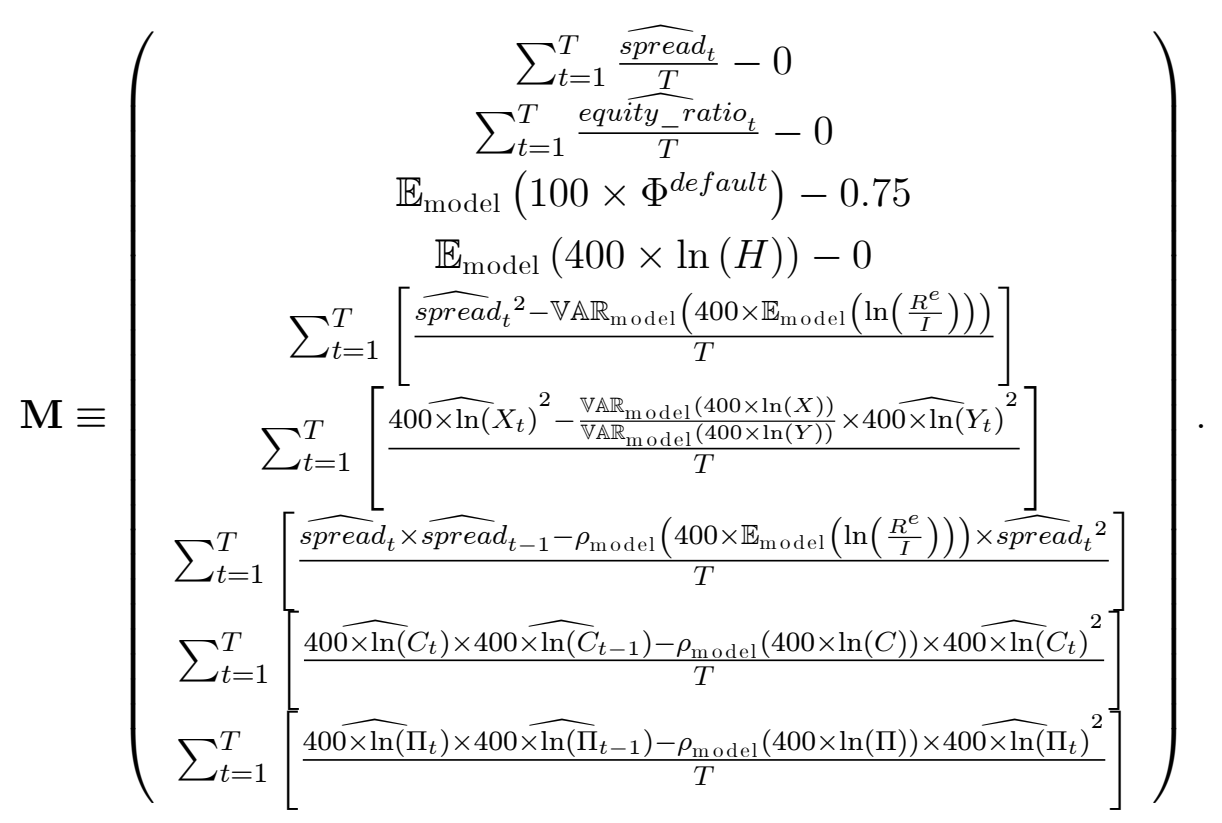




\begin{tabular}{|c|c|c|c|}
\hline Preference and Technological Parameters & Parameter & Value & Parameterization Source \\
\hline Households' Intertemporal Discount Factor & $0<\beta<1$ & 0.990 & Bernanke et al. (1999) \\
\hline Households' Inverse of the Intertemporal Elasticity of Substitution & $\chi \geq 0$ & 1 & Bernanke et al. (1999) \\
\hline Households' Inverse of the Frisch Elasticity of Labor Supply & $\xi \geq 0$ & $\frac{1}{3}$ & Bernanke et al. (1999) \\
\hline Households' Scaling Parameter on Labor Disutility & $\kappa \geq 0$ & 0.738 & SMM estimate \\
\hline Households' Habit Parameter & $0 \leq b \leq 1$ & 0.738 & SMM estimate \\
\hline Elasticity of Substitution Across Varieties & $\epsilon>1$ & 10 & Basu (1996) \\
\hline Capital Share & $0 \leq \alpha \leq 1$ & 0.350 & Bernanke et al. (1999) \\
\hline Entrepreneurial Labor Share & $0 \leq \vartheta \leq 1$ & 0.010 & Bernanke et al. (1999) \\
\hline Depreciation Rate & $0<\delta \leq 1$ & 0.025 & Bernanke et al. (1999) \\
\hline \multicolumn{4}{|l|}{ Adjustment Cost $\mathscr{G}$ Agency Cost Parameters } \\
\hline Capital Adjustment Cost & $\varphi_{k}>0$ & 3.369 & SMM estimate \\
\hline Rotemberg (1982) Price Adjustment Cost & $\varphi_{p} \geq 0$ & 121.730 & SMM estimate \\
\hline Monitoring Cost & $0 \leq \mu<1$ & 0.145 & SMM estimate \\
\hline Survival Rate of Entrepreneurs & $0<\gamma<1$ & 0.978 & SMM estimate \\
\hline \multicolumn{4}{|l|}{ Taylor Rule Policy Parameters } \\
\hline Interest Rate Smoothing & $0 \leq \rho_{i}<1$ & 0.836 & Born and Pfeifer (2014) \\
\hline Sensitivity to Inflation Deviations from Target & $\psi_{\pi}>1$ & 1.777 & Born and Pfeifer (2014) \\
\hline Sensitivity to Output Growth & $\psi_{x}>0$ & 0.319 & Born and Pfeifer (2014) \\
\hline \multicolumn{4}{|l|}{ Exogenous Shock Parameters } \\
\hline Unconditional Std. Dev. of Idiosyncratic Risk Shock & $\sigma_{\omega}>0$ & 0.300 & SMM estimate \\
\hline Persistence of the Stochastic Volatility of Idiosyncratic Risk Shock & $0<v_{\omega}<1$ & 0.966 & SMM estimate \\
\hline Std. Dev. of the Stochastic Volatility of Idiosyncratic Risk Shock & $\eta_{\omega} \geq 0$ & 0.0254 & SMM estimate \\
\hline TFP Shock Persistence & $0<\rho_{a}<1$ & 0.814 & Born and Pfeifer (2014) \\
\hline TFP Shock Unconditional Standard Deviation & $\sigma_{a}>0$ & 0.0054 & Born and Pfeifer (2014) \\
\hline Persistence of the Stochastic Volatility on TFP & $0<v_{a}<1$ & 0.632 & Born and Pfeifer (2014) \\
\hline Std. Dev. of the Stochastic Volatility on TFP & $\eta_{a} \geq 0$ & 0.312 & Born and Pfeifer (2014) \\
\hline Monetary Shock Persistence & $0<\rho_{m}<1$ & 0.367 & Born and Pfeifer (2014) \\
\hline Monetary Shock Unconditional Standard Deviation & $\sigma_{m}>0$ & 0.0014 & Born and Pfeifer (2014) \\
\hline Persistence of the Stochastic Volatility of Monetary Shock & $0<v_{m}<1$ & 0.921 & Born and Pfeifer (2014) \\
\hline Std. Dev. of the Stochastic Volatility of Monetary Shock & $\eta_{m} \geq 0$ & 0.363 & Born and Pfeifer (2014) \\
\hline
\end{tabular}

Note: SMM refers to the Simulated Method of Moments estimation method described in Section 3. 
Table 2. Moments Used to Set Values of $\kappa, b, \varphi_{k}, \varphi_{p}, \gamma, \mu, \sigma_{\omega}, v_{\omega}$, and $\eta_{\omega}$

\begin{tabular}{|c|c|c|c|}
\hline Variable & Moment & Value & Data Source \\
\hline 1. Mean credit spread & $400 \times \mathbb{E}\left(\mathbb{E}_{t}\left(\ln \left(\frac{R_{t+1}^{e}}{I_{t}}\right)\right)\right)$ & 2.29 & $\begin{array}{l}\text { Spread between Moody's seasoned Baa corporate bond } \\
\text { and 10-year Treasury rate (constant maturity) }\end{array}$ \\
\hline 2. Mean equity ratio & $100 \times \mathbb{E}\left(\frac{N_{t}}{P_{t} Q_{t} K_{t+1}}\right)$ & 52.14 & $\begin{array}{l}\text { (Net worth/Total assets)x100 } \\
\text { (Non-financial corporate business) }\end{array}$ \\
\hline 3. Mean quarterly default probability & $100 \times \mathbb{E}\left(\Phi_{t}^{\text {default }}\right)$ & 0.75 & Bernanke et al. (1999) \\
\hline 4. Mean log hours & $400 \times \mathbb{E}\left(\ln \left(H_{t}\right)\right)$ & 0 & Normalization \\
\hline 5. Variance of credit spread & $\mathbb{V} \mathbb{R}\left(400 \times \mathbb{E}_{t}\left(\ln \left(\frac{R_{t+1}^{e}}{I_{t}}\right)\right)\right)$ & 0.52 & $\begin{array}{l}\text { Spread between Moody's seasoned Baa corporate bond } \\
\text { and 10-year Treasury rate (constant maturity) }\end{array}$ \\
\hline 6. $\operatorname{Var}($ investment)/Var(output) & $\frac{\mathbb{V} \mathbb{A} \mathbb{R}\left(400 \times \ln \left(X_{t}\right)\right)}{\mathbb{V} \mathbb{R}\left(400 \times \ln \left(Y_{t}\right)\right)}$ & 17.85 & NIPA fixed investment plus consumer durables \\
\hline 7. Autocorrelation of the credit spread & $\rho\left(400 \times \mathbb{E}_{t}\left(\ln \left(\frac{R_{t+1}^{e}}{I_{t}}\right)\right)\right)$ & 0.90 & $\begin{array}{l}\text { Spread between Moody's seasoned Baa corporate bond } \\
\text { and 10-year Treasury rate (constant maturity) }\end{array}$ \\
\hline 8. Autocorrelation of consumption & $\rho\left(400 \times \ln \left(C_{t}\right)\right)$ & 0.90 & NIPA non-durable consumption \\
\hline 9. Autocorrelation of inflation & $\rho\left(400 \times \ln \left(\Pi_{t}\right)\right)$ & 0.39 & NIPA GDP deflator \\
\hline
\end{tabular}

Note: $\mathbb{E}($.$) denotes unconditional mean, \mathbb{V} \mathbb{R}($.$) denotes unconditional variance, and \rho($.$) denotes the first-order autocorrelation. More details on the data$ sources can be found in Balke et al. (2017b). 
Here, we define $\widehat{\text { spread }} d_{t} \equiv 400 \times\left[\mathbb{E}_{t}\left(\ln \left(\frac{R_{t+1}^{e}}{I_{t}}\right)\right)-\mathbb{E}_{\text {model }}\left(\ln \left(\frac{R^{e}}{I}\right)\right)\right]$, equity_ratio ${ }_{t} \equiv$

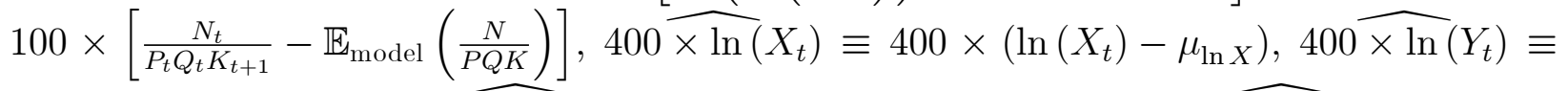
$400 \times\left(\ln \left(Y_{t}\right)-\mu_{\ln Y}\right), 400 \widehat{\times \ln }\left(C_{t}\right) \equiv 400 \times\left(\ln \left(C_{t}\right)-\mu_{\ln C}\right)$, and $400 \widehat{\times \ln \left(\Pi_{t}\right)} \equiv 400 \times$ $\left(\ln \left(\Pi_{t}\right)-\mu_{\ln \Pi}\right)$ with $\mu_{\ln Z}$ being the sample mean of the corresponding variable $Z_{t}$ in logs. $\mathbb{E}_{\text {model }}(\cdot), \mathbb{V} \mathbb{R}_{\text {model }}(\cdot)$, and $\rho_{\text {model }}(\cdot)$ are the simulated unconditional mean, unconditional variance, and first-order autocorrelation, all of them implied by the model solution's pruned third-order approximation. For the mean default probability $\left(100 \times \Phi_{t}^{\text {default }}\right)$ and mean hours worked $\left(400 \times \ln \left(H_{t}\right)\right)$ no sample data was used; the target moments were normalized to 0.75 (as in Carlstrom and Fuerst (1997) and Bernanke et al. (1999)) and zero, respectively. ${ }^{18}$

We select the means of the credit spread $\left(400 \times \mathbb{E}_{t}\left(\ln \left(\frac{R_{t+1}^{e}}{I_{t}}\right)\right)\right)$, the equity ratio $(100 \times$ $\left.\frac{N_{t}}{P_{t} Q_{t} K_{t+1}}\right)$, and the default probability $\left(100 \times \Phi_{t}^{\text {default }}\right)$ as well as the variance and first-order autocorrelation of the credit spread $\left(\widehat{\text { sprea }}_{t}\right)$ to determine the values of $\gamma, \mu, \sigma_{\omega}, v_{\omega}$, and $\eta_{\omega}$. We use the variance of investment $\left(400 \times \ln \left(X_{t}\right)\right)$ relative to that of output $\left(400 \times \ln \left(Y_{t}\right)\right)$ as well as the autocorrelations for inflation $\left(400 \times \ln \left(\Pi_{t}\right)\right)$ and nondurable consumption $\left(400 \times \ln \left(C_{t}\right)\right)$ to pin down the values of $\varphi_{k}, \varphi_{p}$, and $b$, respectively. Finally, the scaling disutility of household labor $\kappa$ sets the average hours worked $\left(400 \times \ln \left(H_{t}\right)\right)$ to zero so household and entrepreneurial labor supply are about the same.

Simulated variances and autocorrelations are based on 20,000 simulated values. The weighting matrix $\mathbf{W}$ is the identity matrix. For each parameter value evaluated, the same random number seed was used to generate the simulated samples. The estimated values for the vector $\left(\kappa, b, \varphi_{k}, \varphi_{p}, \gamma, \mu, \sigma_{\omega}, v_{\omega}\right.$, and $\left.\eta_{\omega}\right)$ are then reported in Table 1 . Our estimates of $\gamma, \mu$, and $\sigma_{\omega}$ are similar to those in Bernanke et al. (1999) and Martínez-García (2014) which do not feature any form of stochastic volatility. The parameters for $v_{\omega}$ and $\eta_{\omega}$ are not very far from those that describe the micro-uncertainty (or financial risk) shocks in Christiano et al. (2014) and Cesa-Bianchi and Fernández-Corugedo (2018). ${ }^{19}$ Similarly, the parameters for $b, \varphi_{k}$, and $\varphi_{p}$ are all well within the ranges typically seen in the literature. ${ }^{20}$

\footnotetext{
${ }^{18}$ In practice, we add a tiny bit of sampling noise to the moment conditions for the default probability and mean hours for computational convenience so we can include them along with the other moments in the same computer subroutine.

${ }^{19}$ Our estimation strategy recovers the parameters of micro-uncertainty shocks from macro-financial data (the spread between Moody's seasoned Baa corporate bond and the 10-year Treasury rate and net worth over total assets in the U.S. non-financial corporate sector) while Cesa-Bianchi and Fernández-Corugedo (2018) use the approach of Chugh (2016) and the annual data from the Census panel of manufacturing establishments over the 1972 - 2009 sample period from Bloom et al. (2018). Yet our estimates are similar to those reported by Cesa-Bianchi and Fernández-Corugedo (2018) albeit with a somewhat higher persistence (0.966 vs. 0.86) that is more congruent with the persistence indicated in Christiano et al. (2014).

${ }^{20}$ References for $b$ include Christiano et al. (2005), Smets and Wouters (2007), and Christiano et al.
} 


\section{Quantitative Findings}

\subsection{Business Cycle Moments}

Table 3, Table 4, and Table 5 display business cycle statistics implied by the estimated benchmark model and by various other variants where we shut down different features each time. In particular, we examine the estimated benchmark $(M 1)$ against alternative specifications where all stochastic volatilities are shut down $\left(\eta_{\omega}=\eta_{a}=\eta_{m}=0, M 2\right)$, where each stochastic volatility is shut down individually $\left(\eta_{\omega}=0, M 3 ; \eta_{a}=0, M 4 ; \eta_{m}=0, M 5\right)$, where financial frictions are shut down $(\mu=0, M 6)$, and where nominal price rigidities are shut down $\left(\varphi_{p}=0, M 7\right)$. Furthermore, we also consider Epstein-Zin preferences to explore the case of high risk aversion separately from the intertemporal elasticity of substitution (M8). ${ }^{21}$

Table 3 reports the standard deviation of output and the standard deviation of the other key macro variables of interest relative to that of output. We compute those moments in the data as well as for the different model specifications under consideration $(M 1-M 8)$. Table 4 shows the first-order autocorrelation (persistence) of the key macro variables and Table 5 displays the correlations of the key macro variables with output (cyclicality) and with the endogenous credit spread, both in the data and across all model specifications $(M 1-M 8)$. Most of these business cycle moments were not used to estimate the structural parameters under the SMM estimation strategy discussed in Section 3. Hence, comparing the empirical against the simulated (not-used-for-estimation) moments provides a measure of cross-validation for the benchmark model (M1). Moreover, by isolating the individual contributions from the most salient modeling features ( $M 1$ vs. $M 2-M 8$ ), we establish the relative importance of each feature in accounting for the observed U.S. business cycles. ${ }^{22}$

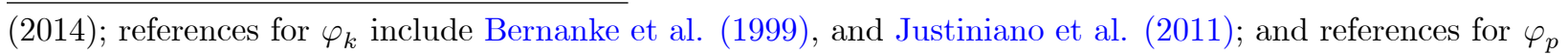
include Carlstrom et al. (2010) and Ascari and Sbordone (2014).

${ }^{21} \mathrm{We}$ specify Epstein-Zin preferences as in Swanson (2018). There $V_{t}=u\left(C_{t}-b C_{t-1}, H_{t}\right)-$ $\beta\left[\mathbb{E}_{t}\left(-V_{t+1}\right)^{1-\nu}\right]^{\frac{1}{1-\nu}}$ with the utility kernel given as $u\left(C_{t}-b C_{t-1}, H_{t}\right) \equiv \frac{\left(C_{t}-b C_{t-1}\right)^{1-\chi}}{1-\chi}-\kappa \frac{H_{t}^{1+\xi}}{1+\xi}$. Our kernel includes internal habits in the additively separable benchmark case in (1). We choose the Epstein-Zin preference parameter $\nu$ according to Swanson (2018) (equation 23) and Andreasen et al. (2018) (online appendix). Hence, we set the value of $\nu$ at -113.11 so that the resulting coefficient of relative risk aversion is 75 and the value of the inverse of the intertemporal elasticity of substitution $\chi$ is 2 . We also considered Jaimovich-Rebelo preferences instead of the additively separable preferences in our benchmark. We found, however, that conventional calibrations of the Jaimovich-Rebelo utility function do not change much our results qualitatively and even quantitatively.

${ }^{22}$ We calculated the same moments in Table 3, Table 4, and Table 5 for the unpruned third-order approximation of the model solution and got results virtually identical to the prunded ones reported here. 
Business Cycle Volatility Comparing the benchmark model (M1) with the model without stochastic volatilities (M2) in Table 3, we observe that the stochastic volatility is an important contributor to the overall volatility of output - output volatility is about $40 \%$ lower in the model without any stochastic volatility. Of the various sources of uncertainty included in the benchmark model, monetary policy uncertainty contributes the most to output volatility (compare M2 vs. M5). In terms of relative variability, we observe that shutting down some or all the stochastic volatilities (as we do in $M 2-M 5$ ) does not have a dramatic impact on the standard deviations of other macro variables (consumption, hours worked, real wages, price markups or inflation) relative to the standard deviation of output.

We also find that the relative volatilities of the equity ratio $\left(100 \times \frac{N_{t}}{P_{t} Q_{t} K_{t+1}}\right)$ and of the credit spread $\left(400 \times \mathbb{E}_{t}\left(\ln \left(\frac{R_{t+1}^{e}}{I_{t}}\right)\right)\right)$ are fairly consistent with the data and largely unchanged with or without macro-uncertainty (M1 vs. M4). However, they are larger by as much as $50 \%$ when we exclude monetary policy uncertainty ( $M 1$ vs. $M 5$ ). The volatilities of these two financial variables relative to output decline to near zero if micro-uncertainty is excluded (M1 vs. M3) while, at the same time, the relative volatility of investment falls by as much as $6 \%$. We infer from all of this that: 1 , macro-uncertainty is of second-order importance to explain volatility over the business cycles; and 2, monetary policy uncertainty is an important contributor to macro volatility while micro-uncertainty is important for financial volatility (the equity ratio and credit spread) and for investment volatility.

Without financial frictions $(M 6)$, the credit spread becomes $s\left(\frac{P_{t} Q_{t} K_{t+1}}{N_{t}}, \sigma_{\omega, t}\right) \equiv 1$ and micro-uncertainty drops out and has no effect on the economy as can be noted from the efficiency condition in (14) pins down the entrepreneurs' demand for capital. We disentangle the impact of financial frictions ( $M 6$ vs. $M 1$ ) by parts. On the one hand, we observe that output volatility is almost $8 \%$ higher and the relative volatility of investment is about $10 \%$ lower in a model without financial frictions (which also excludes micro-uncertainty) (M6) than in a model with financial frictions but no micro-uncertainty (M3). On the other hand, we also find that output volatility is about $3.5 \%$ lower and the relative volatility of investment is about $6 \%$ lower in the case with financial frictions but no micro-uncertainty $(M 3)$ than in the benchmark model with financial frictions and micro-uncertainty $(M 1)$.

Accordingly, we argue that: (a), adding financial frictions alone tends to mitigate output volatility but at the expense of a significantly higher investment volatility, and (b), adding micro-uncertainty to the model with financial frictions leads to higher output volatility and, particularly, leads to higher investment volatility relative to that of output. Therefore, when comparing the benchmark $(M 1)$ against the model without financial frictions (and without 
micro-uncertainty) (M6), the effects in (a) and (b) push in the same direction resulting in lower relative investment volatility while the negative effect of (b) limits the higher output volatility that would result from the effect of (a). Hence, eliminating financial frictions significantly lowers the relative volatility of investment with respect to that of output by as much as $15 \%$ and, counterfactually, brings down the relative volatilities of the equity ratio and the credit spread to near zero. ${ }^{23}$ This, however, has modest effects on the variability of output, which is about $4 \%$ higher than in the benchmark model (M1), and on most of the relative volatilities for other macro variables except for investment.

Without monetary policy uncertainty $(M 5)$ as well as with costless price adjustments (M7), the volatility of output falls by about $35 \%$ and $40 \%$, respectively, relative to the benchmark (M1) and counterfactually below the observed U.S. output volatility. The relative volatility of the credit spread and the equity ratio nearly doubles compared to what we observe in the benchmark model (compare $M 5$ and $M 7$ vs. $M 1$ ), while changes in the relative volatility of investment are otherwise very minor. All these findings suggest that the impact of monetary policy uncertainty operates primarily through the standard New Keynesian channels rather than through credit frictions and the financing of capital.

While the volatility of other non-financial variables relative to that of output appears largely similar with or without monetary policy uncertainty ( $M 1$ vs. $M 5$ ), removing nominal rigidities (as in $M 7$ ) can have counterfactual implications for them. Under the Taylor (1993) rule in (33) (and even when the central bank responds to output deviations from steady state instead of the output growth), the relative volatility of the nominal interest rate shoots up more than twofold and the relative volatility of inflation more than fourfold in the model without nominal rigidities (compare $M 7$ vs. $M 1$ or even $M 5$ with nominal rigidities but no monetary policy uncertainty). Removing nominal rigidities ( $M 7)$ also brings down the volatility of price markups to zero which is thought as quite implausible. It also has implications along the consumption-labor margin increasing the volatility of consumption relative to output by about $20 \%$ while concurrently decreasing the relative volatility of hours worked by a whopping $65 \%$ when $M 7$ is compared to $M 1$ or $M 5$.

Using Epstein-Zin preferences with a relatively high risk aversion (M8) lowers the volatility of consumption relative to output well below what we observe in the data (about $62.5 \%$ lower) while increasing the relative volatility of investment somewhat (by about 9\%). It

\footnotetext{
${ }^{23}$ Including capital adjustment costs in the benchmark model, $\varphi_{k}>0$, introduces a real rigidity which is crucial to align the relative volatility of investment with that found in the data. Similar to removing financial frictions, removing this real rigidity also contributes to produce counterfactually higher investment volatility but, in contrary, does so while still allowing variation in the equity ratio and the credit spread.
} 
also decreases the overall output volatility relative to that of the estimated benchmark (M1) by about $9 \%$ and also produces a relative volatility of consumption about $37 \%$ lower. This suggests that, when risk aversion is high, households beef up their precautionary savings to self-insure against future risks contributing to mitigate the effects of uncertainty on output volatility but, in the process, inducing counterfactually smooth consumption dynamics.

Business Cycle Persistence and Cyclicality From Table 4, we find that introducing stochastic volatility or financial frictions has little effect on the autocorrelations of the model. The only notable exception to this is that the persistence on inflation and on the nominal interest rate is substantially lower while the persistence on output and investment is a touch higher in the model without nominal rigidities (M7) than in the benchmark $(M 1)$. This suggests that price adjustment costs have a major effect on the persistence of nominal variables and only some modest impacts on the persistence of real macroeconomic variables. Interestingly, the persistence of macro variables is largely unaffected by financial frictions even though loan contracts open up an important conduit for the propagation of shocks through the funding-of-capital channel.

The benchmark model $(M 1)$ closely matches the persistence of consumption and the credit spread, but these moments are targeted in our SMM estimation strategy. The inflation persistence implied by the benchmark model $(M 1)$ is a bit higher than its targeted empirical counterpart, though. The persistence of the benchmark (M1) on output, investment, and hours worked is lower than in the data. We argue that this is partly because of the well-known consumption-smoothing puzzle (Caballero (1990)): While output tends to be as persistent as consumption in the data, the benchmark model $(M 1)$ — which is estimated to match the relative volatility of investment - generates instead some excess-consumption-smoothness (see Table 3). This in turn comes with excess-consumption-persistence and low investment persistence. Hence, the findings in Table 4 suggest that removing price adjustment costs (M7) can partly mitigate this issue by increasing the output persistence and lowering the inflation persistence. Similar results are found if nominal rigidities are modeled with Calvo (1983) rather than Rotemberg (1982) pricing. ${ }^{24}$

\footnotetext{
${ }^{24}$ Working with Calvo (1983) pricing, we set the stickiness parameter to 0.8 implying an average price duration of 5 quarters that is reasonably close to the implied duration in the benchmark model estimated under Rotemberg (1982) price adjustment costs instead.
} 
Table 3. Simulated and Empirical Business Cycle Volatilities for Various Models

\begin{tabular}{cccccccccc}
\hline \hline & Data & M1 & M2 & M3 & M4 & M5 & M6 & M7 & M8 \\
\hline$s t d v\left(z_{t}\right)(\%)$ & & & & & & & & & \\
\hline$z_{t} \equiv$ Output & 4.62 & 4.47 & 2.58 & 4.31 & 4.40 & 2.95 & 4.65 & 2.72 & 4.03 \\
\hline$s t d v\left(z_{t}\right) / s t d v$ (Output) & & & & & & & & & \\
\hline$z_{t} \equiv$ Consumption & 0.64 & 0.38 & 0.44 & 0.38 & 0.36 & 0.44 & 0.35 & 0.53 & 0.24 \\
Investment* & 4.23 & 4.19 & 3.77 & 3.95 & 4.24 & 4.30 & 3.56 & 4.12 & 4.61 \\
Hours Worked & 1.66 & 1.61 & 1.66 & 1.61 & 1.60 & 1.67 & 1.55 & 0.55 & 1.69 \\
Real Wages & 0.96 & 1.54 & 1.51 & 1.60 & 1.56 & 1.35 & 1.50 & 1.19 & 1.74 \\
Price Markup & - & 2.15 & 2.21 & 2.22 & 2.16 & 2.04 & 2.10 & 0.00 & 2.36 \\
Inflation & 0.14 & 0.42 & 0.42 & 0.44 & 0.43 & 0.38 & 0.41 & 1.79 & 0.46 \\
Interest Rate & 0.59 & 0.16 & 0.17 & 0.15 & 0.16 & 0.18 & 0.13 & 0.34 & 0.20 \\
Equity Ratio & 0.58 & 0.32 & 0.06 & 0.05 & 0.32 & 0.48 & 0.01 & 0.52 & 0.35 \\
Credit Spread & 0.16 & 0.15 & 0.02 & 0.02 & 0.15 & 0.23 & 0.00 & 0.25 & 0.17 \\
\hline \hline
\end{tabular}

Note: The endogenous variables included are output $\left(400 \times \ln \left(Y_{t}\right)\right)$, household consumption $\left(400 \times \ln \left(C_{t}\right)\right)$, investment $\left(400 \times \ln \left(X_{t}\right)\right)$, hours worked by households $\left(400 \times \ln \left(H_{t}\right)\right)$, real wages $\left(400 \times \ln \left(\frac{W_{t}}{P_{t}}\right)\right)$, price markup $\left(-400 \times \ln \left(P_{t}^{w r}\right)\right)$, inflation $\left(400 \times \ln \left(\Pi_{t}\right)\right)$, nominal interest rate $\left(400 \times \ln \left(I_{t}\right)\right)$, equity ratio $\left(100 \times \frac{N_{t}}{P_{t} Q_{t} K_{t+1}}\right)$, and credit spread $\left(400 \times \mathbb{E}_{t}\left(\ln \left(\frac{R_{t+1}^{e}}{I_{t}}\right)\right)\right)$. We extract the cyclical component of all these series by HP-filtering them with a one-sided filter using a lambda of 1600 and a power of 2 , except for the equity ratio and the nominal interest rate that are demeaned instead. More details on the data sources can be found in Balke et al. (2017b). The table shows the standard deviation of output and the standard deviation of all other endogenous variables relative to the standard deviation of output. We report the results for the following variants of the model: M1 = benchmark model, M2 = without all stochastic volatilities, M3 = without micro-uncertainty only, M4 = without TFP stochastic volatility only, M5 = without monetary stochastic volatility, M6 = without financial frictions, M7 = without nominal rigidities, and M8 = Epstein-Zin preferences with high risk aversion.

* These data moments are used to estimate the benchmark model by the simulated method of moments, all others are not. 
Table 4. Simulated and Empirical Business Cycle Persistence for Various Models

\begin{tabular}{cccccccccc}
\hline \hline & Data & M1 & M2 & M3 & M4 & M5 & M6 & M7 & M8 \\
\hline$\rho\left(z_{t}, z_{t-1}\right)$ & & & & & & & & & \\
\hline$z_{t} \equiv$ Output & 0.91 & 0.63 & 0.68 & 0.64 & 0.62 & 0.67 & 0.63 & 0.73 & 0.60 \\
Consumption* & 0.90 & 0.90 & 0.91 & 0.89 & 0.89 & 0.91 & 0.89 & 0.91 & 0.90 \\
Investment & 0.93 & 0.58 & 0.58 & 0.55 & 0.58 & 0.64 & 0.56 & 0.68 & 0.58 \\
Hours Worked & 0.96 & 0.56 & 0.55 & 0.57 & 0.57 & 0.54 & 0.56 & 0.54 & 0.55 \\
Real Wages & 0.73 & 0.57 & 0.59 & 0.57 & 0.56 & 0.60 & 0.56 & 0.66 & 0.57 \\
Price Markup & - & 0.54 & 0.53 & 0.55 & 0.55 & 0.52 & 0.54 & - & 0.54 \\
Inflation* & 0.39 & 0.52 & 0.51 & 0.52 & 0.52 & 0.51 & 0.52 & 0.01 & 0.52 \\
Interest Rate & 0.96 & 0.83 & 0.85 & 0.83 & 0.83 & 0.87 & 0.83 & 0.61 & 0.85 \\
Equity Ratio & 0.96 & 0.99 & 0.97 & 1.00 & 0.99 & 0.99 & 0.99 & 0.99 & 0.99 \\
Credit Spread* & 0.89 & 0.88 & 0.96 & 0.96 & 0.88 & 0.88 & 0.93 & 0.88 & 0.89 \\
\hline \hline
\end{tabular}

Note: The endogenous variables included are output $\left(400 \times \ln \left(Y_{t}\right)\right)$, household consumption $\left(400 \times \ln \left(C_{t}\right)\right)$, investment $\left(400 \times \ln \left(X_{t}\right)\right)$, hours worked by households $\left(400 \times \ln \left(H_{t}\right)\right)$, real wages $\left(400 \times \ln \left(\frac{W_{t}}{P_{t}}\right)\right)$, price markup $\left(-400 \times \ln \left(P_{t}^{w r}\right)\right)$, inflation $\left(400 \times \ln \left(\Pi_{t}\right)\right)$, nominal interest rate $\left(400 \times \ln \left(I_{t}\right)\right)$, equity ratio $\left(100 \times \frac{N_{t}}{P_{t} Q_{t} K_{t+1}}\right)$, and credit spread $\left(400 \times \mathbb{E}_{t}\left(\ln \left(\frac{R_{t+1}^{e}}{I_{t}}\right)\right)\right)$. We extract the cyclical component of all these series by HP-filtering them with a one-sided filter using a lambda of 1600 and a power of 2, except for the equity ratio and the nominal interest rate that are demeaned instead. More details on the data sources can be found in Balke et al. (2017b). The table shows the firstorder autocorrelations. We report the results for the following variants of the model: M1 = benchmark model, M2 = without all stochastic volatilities, M3 = without micro-uncertainty only, M4 = without TFP stochastic volatility only, M5 = without monetary stochastic volatility, M6 = without financial frictions, M7 $=$ without nominal rigidities, and M8 $=$ Epstein-Zin preferences with high risk aversion.

* These data moments are used to estimate the benchmark model by the simulated method of moments, all others are not. 
Table 5. Simulated and Empirical Business Cycle Cyclicality for Various Models

\begin{tabular}{cccccccccc}
\hline \hline & Data & M1 & M2 & M3 & M4 & M5 & M6 & M7 & M8 \\
\hline$\rho\left(z_{t}\right.$, Output $)$ & & & & & & & & & \\
\hline$z_{t} \equiv$ Output & 1.00 & 1.00 & 1.00 & 1.00 & 1.00 & 1.00 & 1.00 & 1.00 & 1.00 \\
Consumption & 0.90 & 0.70 & 0.80 & 0.77 & 0.70 & 0.67 & 0.75 & 0.73 & 0.61 \\
Investment & 0.93 & 0.94 & 0.95 & 0.96 & 0.94 & 0.92 & 0.97 & 0.89 & 0.96 \\
Hours Worked & 0.88 & 0.79 & 0.55 & 0.77 & 0.83 & 0.53 & 0.80 & -0.11 & 0.75 \\
Real Wages & 0.04 & 0.94 & 0.96 & 0.97 & 0.94 & 0.89 & 0.97 & 0.89 & 0.94 \\
Price Markup & - & -0.80 & -0.61 & -0.81 & -0.84 & -0.54 & -0.81 & - & -0.81 \\
Inflation & 0.35 & 0.83 & 0.69 & 0.84 & 0.86 & 0.62 & 0.84 & -0.12 & 0.83 \\
Interest Rate & -0.02 & -0.49 & -0.55 & -0.58 & -0.49 & -0.35 & -0.56 & -0.38 & -0.40 \\
Equity Ratio & -0.02 & 0.06 & -0.03 & -0.10 & 0.06 & 0.10 & -0.06 & 0.11 & 0.07 \\
Credit Spread & -0.51 & -0.07 & 0.06 & 0.10 & -0.07 & -0.12 & 0.00 & -0.11 & -0.08 \\
\hline$\rho\left(z_{t}\right.$, Credit Spread $)$ & & & & & & & & -0.11 & -0.08 \\
$z_{t} \equiv$ Output & -0.51 & -0.07 & 0.06 & 0.10 & -0.07 & -0.12 & 0.00 & -0.00 \\
Consumption & -0.51 & -0.04 & 0.09 & 0.10 & -0.05 & -0.06 & 0.00 & -0.03 & -0.06 \\
Investment & -0.42 & -0.10 & 0.04 & 0.08 & -0.10 & -0.15 & 0.00 & -0.16 & -0.10 \\
Hours Worked & -0.44 & -0.03 & 0.14 & 0.15 & -0.03 & -0.05 & 0.01 & -0.15 & -0.03 \\
Real Wages & -0.04 & -0.01 & 0.08 & 0.11 & -0.01 & -0.04 & 0.01 & -0.02 & -0.03 \\
Price Markup & - & 0.00 & -0.13 & -0.14 & 0.00 & 0.01 & -0.01 & - & 0.00 \\
Inflation & -0.18 & 0.01 & 0.12 & 0.14 & 0.00 & -0.01 & 0.01 & -0.00 & -0.00 \\
Interest Rate & -0.61 & -0.36 & -0.52 & -0.30 & -0.36 & -0.49 & -0.01 & -0.38 & -0.36 \\
Equity Ratio & 0.02 & 0.18 & -0.99 & -0.99 & 0.18 & 0.18 & -0.11 & 0.19 & 0.16 \\
Credit Spread & 1.00 & 1.00 & 1.00 & 1.00 & 1.00 & 1.00 & 1.00 & 1.00 & 1.00 \\
\hline \hline
\end{tabular}

Note: The endogenous variables included are output $\left(400 \times \ln \left(Y_{t}\right)\right)$, household consumption $\left(400 \times \ln \left(C_{t}\right)\right)$, investment $\left(400 \times \ln \left(X_{t}\right)\right)$, hours worked by households $\left(400 \times \ln \left(H_{t}\right)\right)$, real wages $\left(400 \times \ln \left(\frac{W_{t}}{P_{t}}\right)\right)$, price markup $\left(-400 \times \ln \left(P_{t}^{w r}\right)\right)$, inflation $\left(400 \times \ln \left(\Pi_{t}\right)\right)$, nominal interest rate $\left(400 \times \ln \left(I_{t}\right)\right)$, equity ratio $\left(100 \times \frac{N_{t}}{P_{t} Q_{t} K_{t+1}}\right)$, and credit spread $\left(400 \times \mathbb{E}_{t}\left(\ln \left(\frac{R_{t+1}^{e}}{I_{t}}\right)\right)\right)$. We extract the cyclical component of all these series by HP-filtering them with a one-sided filter using a lambda of 1600 and a power of 2 , except for the equity ratio and the nominal interest rate that are demeaned instead. More details on the data sources can be found in Balke et al. (2017b). The table shows the contemporaneous correlation with output (cyclicality) and the contemporaneous correlation with the credit spread. We report the results for the following variants of the model: M1 = benchmark model, M2 = without all stochastic volatilities, M3 = without micro-uncertainty only, M4 = without TFP stochastic volatility only, M5 = without monetary policy stochastic volatility, M6 = without financial frictions, M7 = without nominal rigidities, and M8 = Epstein-Zin preferences with high risk aversion. 
From Table 5, we observe that the benchmark model $(M 1)$ gets the cross-correlations of output with other real macro variables largely right. Consumption, investment, and hours worked are procyclical while the price markup is countercyclical. The most notable mismatch with the data is the correlation between output and the real wage. In the U.S. data, real wages are largely acyclical while they appear strongly procyclical in the benchmark model. The benchmark is more imprecise when it comes to pin down the magnitude of the crosscorrelation of output with the nominal and financial variables (inflation, nominal interest rate, equity ratio, and credit spread) even though it gets the sign of the cyclicality right, except for the equity ratio.

We also note that monetary policy uncertainty (see $M 5$ without it) as well as nominal rigidities (see $M 7$ without them) play a substantive role in the simulated cyclicality of inflation and the nominal interest rate. ${ }^{25}$ Comparing models $M 1$ through $M 5$ in Table 5 suggests that including stochastic volatility does not change the correlations of output with other real macro variables all that much, but it does change the output and credit spread correlation in an economically meaningful way. We observe that the model without any form of stochastic volatility $(M 2)$, which is the one that comes closest to the financial frictions model of Bernanke et al. (1999) and Martínez-García (2014), results in procyclical movements in the credit spread. That is, the endogenous credit spreads implied by the financial accelerator mechanism alone fail to match the countercyclical correlation observed in the U.S. data. ${ }^{26}$ Hence, including stochastic volatility (and micro-uncertainty in particular) becomes the key to generate a plausible countercyclical credit spread ( $M 1$ vs. M3).

Even so, the model correlations between output and the credit spread are generally smaller in magnitude than those found in the data. This indicates that a general equilibrium New Keynesian model, even one with credit frictions and micro-uncertainty like ours, still misses part of the interaction between output and the credit spread observed in the U.S.

\subsection{Generalized Impulse Response Analysis}

We conduct an impulse response analysis similar to what is typically done with linear models to investigate the propagation of exogenous shocks. Given the nonlinear nature of the model solution that we pursue here, we use the generalized impulse response approach of Koop et al. (1996) and calculate how the conditional expectation of the pruned third-order

\footnotetext{
${ }^{25}$ We observe that the sensitivity of the policy rule to inflation in particular is another important factor in accounting for the observed empirical comovement.

${ }^{26}$ Faia and Monacelli (2007) provide additional discussion on financial frictions and the countercyclicality of the credit spread.
} 
approximation of endogenous variables $\left(\mathbf{y}_{t}^{r d}\right)$ changes as a result of a shock innovation $\left(\mathbf{v}_{t}\right)$. Specifically, we examine:

$$
\operatorname{GIRF}\left(k, \mathbf{v}_{t}, \mathbf{x}_{t-1}\right) \equiv \mathbb{E}\left[y_{t+k}^{r d} \mid \mathbf{v}_{t}, \mathbf{x}_{t-1}\right]-\mathbb{E}\left[y_{t+k}^{r d} \mid \mathbf{x}_{t-1}\right]
$$

where the state vector of the pruned third-order approximation is $\mathbf{x}_{t}=\left(\mathbf{x}_{t}^{f}, \mathbf{x}_{t}^{s}, \mathbf{x}_{t}^{r d}\right)^{\prime}$. We denote an endogenous variable $k$-periods-ahead generically as $y_{t+k}^{r d}$ (shorthand $\left.k\right) .{ }^{27}$

Given the pruned third-order approximation of the nonlinear model that we use, the impulse responses in (36) do not, in principle, have to be symmetric or scale up with the size of the shock innovation, $\mathbf{v}_{t}$. Furthermore, the impulse responses may be path-dependentconditional on the initial conditions of the state variables. In general, there are many possible initial conditions to evaluate and typically researchers would simply take the initial condition to be a particular realization, say the deterministic steady state or the ergodic (unconditional) mean of the state variables. Unfortunately, while responses conditional on a particular realization are relatively easy to compute, it is not straightforward to evaluate the likelihood of the economy being at that particular initial state.

Our approach is to use the information not only from a particular realization, but from the unconditional distribution implied by the model to choose initial conditions for our impulse response analysis that are economically-relevant. As part of our impulse response analysis, we first get a sense of the average effect of shocks over all possible initial conditions. Then, we concentrate our impulse response analysis on exploring the differences in the propagation of shocks arising from different initial conditions on: (a) the types of uncertainty under consideration, and (b) endogenous variables related to the state (tight or loose) of financial conditions such as the credit spread, the equity ratio, and the nominal interest rate.

\subsubsection{Unconditional Impulse Responses}

We look at the expected (or average) generalized impulse response given the unconditional distribution implied by the model, i.e.,

$$
G I R F_{\text {average }}\left(k, \mathbf{v}_{t}\right)=\int G I R F\left(k, \mathbf{v}_{t}, \mathbf{x}_{t-1}=\mathbf{x}\right) p(\mathbf{x}) d \mathbf{x}
$$

\footnotetext{
${ }^{27}$ We compare simulated generalized impulse responses as in Balke (2000) with the analytical solution for the pruned third-order approximation derived by Andreasen et al. (2018). We also examine the simulated impulse responses from the non-pruned third-order approximation. However, we find little difference between the pruned and non-pruned model solutions, with only very minor deviations noticeable on the responses to monetary policy shocks.
} 
where $p(\mathbf{x})$ is the unconditional density of the state vector $\mathbf{x}$ implied by the model, $k$ is again shorthand for the horizon of the endogenous variable of interest, and $\mathbf{v}_{t}$ refers to the shock innovations. To obtain an estimate of the unconditional distribution of the endogenous variables implied by the model, we simulate the pruned third-order approximation starting at the unconditional mean for 300 time periods. We repeat this 20,000 times to obtain an estimate of the unconditional distribution. We then draw a sample of initial conditions (500 draws), calculate the change in conditional expectations for each initial condition, and average the responses.

The Unconditional Response Patterns Figure 1 displays the average impulse responses for the various shocks in the model. ${ }^{28}$ In general, first-moment TFP and monetary policy shocks have substantially larger effects than macro-uncertainty and monetary policy uncertainty shocks that affect their volatilities (second-moments). Macro-uncertainty shocks cause consumption and investment to fall, and output, hours worked, and inflation to rise while monetary policy uncertainty shocks lead to declines in consumption and increases in investment, output, hours worked, and inflation. However, in the estimated benchmark model $(M 1)$, on average, their responses are of at most second-order importance, even for monetary policy uncertainty shocks whose responses are an order of magnitude larger than the responses to macro-uncertainty. Furthermore, the effects of macro-uncertainty and monetary policy uncertainty on the equity ratio as well as on the credit spread are quite small indicating that the contribution of financial frictions to amplify these two types of uncertainty shocks is quite modest.

Overall, these results are broadly in line with the existing literature on TFP and monetary policy uncertainty which also tends to find small individual effects (see, e.g., FernándezVillaverde et al. (2010) and Born and Pfeifer (2014)). In fact, when examining the importance of stochastic volatility shocks, the existing literature often focuses on the response to a

\footnotetext{
${ }^{28}$ A number of papers - such as Cesa-Bianchi and Fernández-Corugedo (2018) — the literature conduct their analysis calculating responses conditional on the ergodic (unconditional) mean instead of averaging impulse responses over the unconditional distribution of initial conditions, as we do in Figure 1 . Balke et al. (2017b) (Figure 5) illustrates the impulse responses corresponding to Figure 1 under this alternative approach setting the initial condition to be equal to the ergodic (unconditional) mean. The two sets of responses are qualitatively similar, although the average response to first-moment shocks (monetary policy shocks and TFP shocks) is larger in magnitude than the corresponding response starting at the ergodic (unconditional) mean. In turn, the average response for second-moment shocks is almost indistinguishable from the corresponding response computed with respect to the ergodic (unconditional) mean for macroand micro-uncertainty shocks, and displays only quantitatively small differences in response to monetary policy uncertainty.shocks. Such differences between averaging over initial conditions and setting the initial condition at the ergodic (unconditional) mean are likely due to Jensen's inequality.
} 
simultaneous two-standard deviation shock to all sources of uncertainty showcasing episodes of heightened, albeit very infrequent, broad uncertainty. In our subsequent analysis, we also explore tail events over the distribution of the uncertainty shocks and, not surprisingly, reach similar conclusions: Macro-uncertainty and policy uncertainty shocks are most relevant economically at those infrequent times when their size can be fairly large.

Figure 1 also showcases that a second-moment shock - specifically micro-uncertaintycan have first-order economic effects, as its economic impact heightens and propagates through an economy with credit frictions. The effects of a shock to the distribution of entrepreneurial idiosyncratic productivity (micro-uncertainty), on average, are of the same order of magnitude as those of a TFP shock and about half the impact of a monetary policy shock on output. The credit friction that underpins our estimated benchmark model (M1) is key for these findings because it implies that micro-uncertainty shocks cannot be fully insured with the available nominal loan contract. As a result of asymmetric information and costly monitoring, greater micro-uncertainty makes lending to entrepreneurs riskier and leads to a higher default probability and higher credit spreads charged on entrepreneurs. As can be gleaned from the capital demand through the efficiency condition in (14), the resulting higher cost of borrowing reduces the demand for capital and pushes down its price (Tobin's q), but also encourages entrepreneurs to free up more internal funds (increasing the equity ratio). In response to the falling investment, households cut down labor input and save initially less in order to sustain their consumption which over time also gradually declines. Hence, output shrinks quite strongly and inflation falls even though nominal interest rates are cut to provide some accommodation.

Finally, we should note that TFP shocks generate countercyclical patterns of hours worked and inflation that cannot be reconciled with the unconditional comovement seen in Table 5. In turn, qualitatively similar to micro-uncertainty, monetary policy shocks induce a positive comovement between output, consumption, investment, hours worked, and inflation as well as a countercyclical but small credit spread which is more in line with the observed unconditional comovement. ${ }^{29}$ However, monetary policy shocks generate countercyclical movements of the interest rate and cyclical movements of the equity ratio while micro-uncertainty does the opposite. Accordingly, we observe that monetary policy shocks can help explain the comovement of the main real and nominal macro variables found in the data, but micro-uncertainty shocks can deliver similar patterns and their contribution

\footnotetext{
${ }^{29}$ As argued by Basu and Bundick (2017), similar macroeconomic comovement between output, consumption, investment, and hours worked also could arise from other second-moment shocks too (e.g., from uncertainty on preference shocks).
} 
is fundamental to simultaneously match the countercyclical and volatile financial variables (credit spreads, equity ratio, and interest rate) as observed in Table 5. This suggests that micro-uncertainty shocks (or financial risk shocks more broadly) are an important drivers of the business cycle that might be confounded with monetary policy shocks when financial data is not used to discipline the model.

Figure 1. Unconditional Generalized Impulse Responses for the Baseline Model
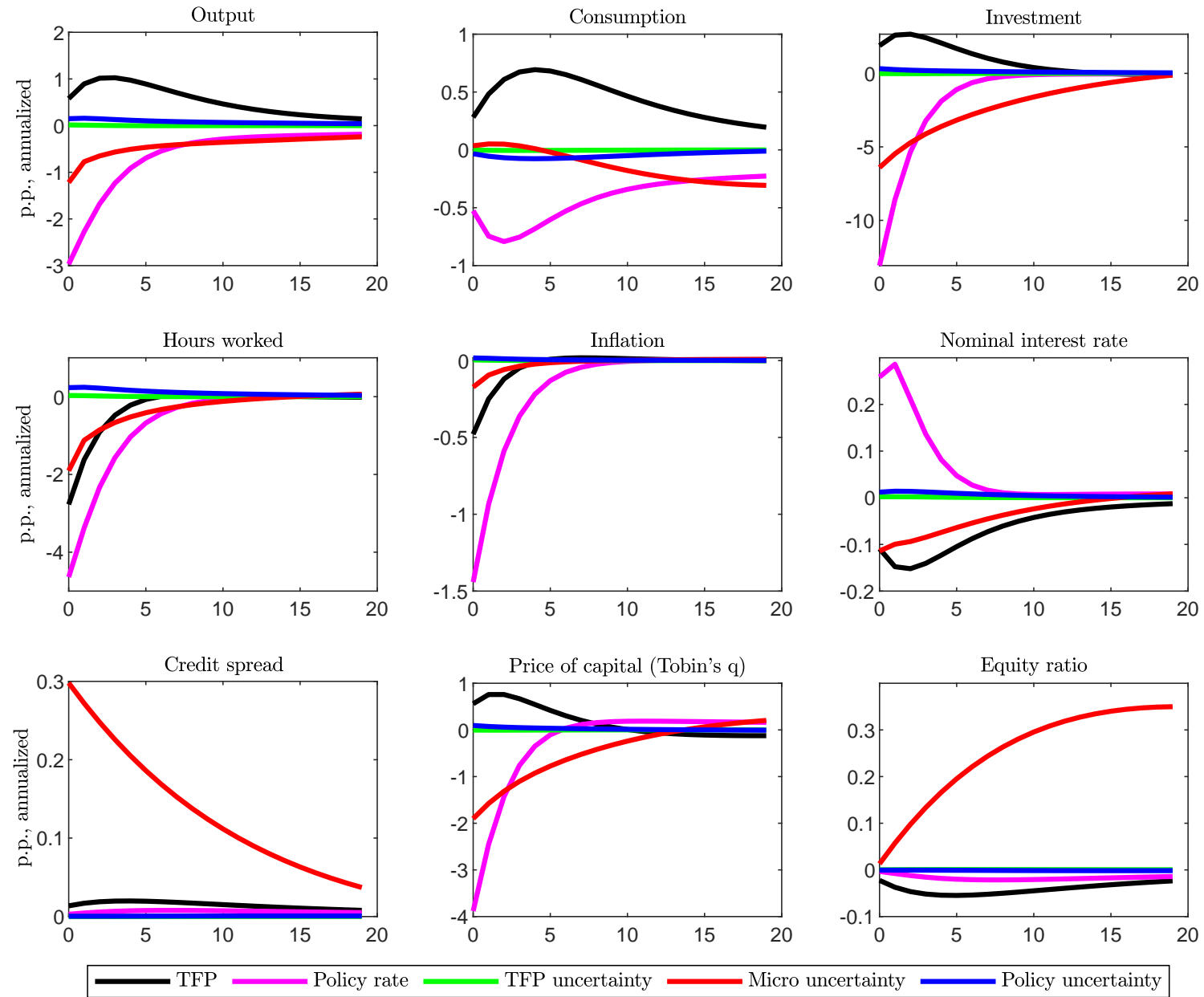

Note: The GIRFs are computed averaging across all initial conditions under the baseline model. All responses are in percentage points, annualized.

\section{The Effect of Key Features of the Model on Unconditional Impulse Responses}

Figure 2 plots the average impulse responses of output as well as the impact on borrowing 
costs through the responses of the credit spread and the nominal interest rate for alternative models. We compare the benchmark $(M 1)$ against the model without credit frictions $(\mu=0$, M6), the model with flexible prices $\left(\varphi_{p}=0, M 7\right)$, and the model with Epstein-Zin preferences allowing for high risk aversion $(M 8)$. We also consider the case where price rigidities are modeled with Calvo (1983) pricing rather than Rotemberg (1982) price adjustment costs and the case where internal habits in consumption are shut down $(b=0)$.

We observe from Figure 2 that, under Epstein-Zin preferences with high relative risk aversion (M8), the response of output to macro- and micro-uncertainty are a touch lower than in the benchmark case $(M 1)$, while the response to monetary policy uncertainty shocks increases noticeably (although its effect remains rather modest). ${ }^{30}$ The higher risk-aversion under Epstein-Zin preferences (M8) typically dampens the effects of first-moment shocks, and most significantly lowers the wealth effects from TFP shocks.

If prices are fully flexible $(M 7)$, monetary policy shocks have no real effects, the impact of micro-uncertainty shocks is lessened, and the effect of TFP shocks on economic activity increases (albeit the output response to a TFP shock in that case is no longer hump-shaped). The effect of the macro-uncertainty and monetary policy uncertainty shocks, already small in the benchmark model $(M 1)$, declines further when we remove nominal rigidities $(M 2)$. Furthermore, the impact of macro-uncertainty shocks on economic activity becomes negative only with flexible prices. In turn, the positive response of output to monetary policy uncertainty still persists although much diminished. These patterns of macro-uncertainty and monetary policy uncertainty appear consistent with the inverse "Oi-Hartman-Abel" effects of uncertainty previously explored in the work of Born and Pfeifer (2014).

The magnitude of the economic boost arising from these inverse "Oi-Hartman-Abel" effects depends on the presence of nominal rigidities, weakening somewhat under Calvo (1983) pricing relative to our benchmark under Rotemberg (1982) price adjustment costs. As argued by Abel (1983), these effects suggest that risk-neutral entrepreneurs operating with a convex cost structure respond with a small investment increase as price uncertainty increases as a result of higher uncertainty. In other words, even when nominal rigidities are low or prices are flexible, an economic impact can still arise in part from convex adjustment costs on capital (real rigidities) which affect the price of physical capital (Tobin's q) and the capital's resale value in (20) and (21). It can also arise in part due to the presence of

\footnotetext{
${ }^{30}$ The precautionary savings motive implies that risk-averse households cut back on consumption expenditure and generally work more today to build up their savings and self-insure against an uncertain future (see, e.g., Carroll and Kimball (2008)). However, in a general equilibrium setting like ours, this mechanism appears to have only a limited effect for time-varying uncertainty even with fairly high risk-aversion ( $M 8)$.
} 
credit frictions since the capital demand is tied to a credit spread - a convex function of the entrepreneurs' equity — which affects the borrowing costs of the entrepreneurs in (14). ${ }^{31}$

The response of output to the micro-uncertainty shock is almost two times larger on impact in the benchmark (M1) than in the flexible prices case $(M 7)$. This shows that credit frictions alone explain only part of the punch the model gets from micro-uncertainty shocks. In other words, inefficiencies in the goods markets (nominal rigidities) are important to amplify the impact of exogenous micro-uncertainty shocks. These results also hold whenever we replace Rotemberg (1982) costs with Calvo (1983) pricing. The most significant difference that emerges being that the average impact on economic activity of monetary policy shocks, and to some extent of policy uncertainty shocks, is significantly attenuated with Calvo (1983) (as seen in Figure 2). The effects of TFP and macro-uncertainty that we obtain also display a degree of attenuation under Calvo (1983) pricing, but the impact on the propagation of micro-uncertainty shocks on real economic activity is almost negligible. ${ }^{32}$

Comparing the benchmark $(M 1)$ with a costless credit monitoring model $(M 6)$, we see that financial frictions do not qualitatively change the average response of the variables of interest to TFP or to monetary policy shocks but do lower their magnitude. The removal of credit monitoring costs does neither appear to alter much the response to macro-uncertainty nor to policy uncertainty shocks (which are already small in the benchmark model, M1), but implies that micro-uncertainty shocks have no effect. In other words, micro-uncertainty shocks matter only in the presence of credit frictions.

Interestingly, removing internal habits on consumption has the effect of dampening the average response of the credit spread to a TFP shock and boosting the average response of output. In contrast, removing habits in consumption attenuates the real effects of microuncertainty without much effect on credit spreads. The absence of consumption habits also worsens the impact of monetary policy shocks on credit spreads and their drag on output. We infer from this that internal habits on consumption downplay the business cycle contribution of micro-uncertainty relative to the contribution of TFP and monetary policy shocks.

In summary, the evidence presented in Figure 2 based on the average responses over all possible initial conditions suggests that the interaction between financial frictions and

\footnotetext{
${ }^{31}$ Fixed costs or partial irreversibilities can also introduce convexities in the model which we have not considered here. Those types of convexities can result in agents delaying purchases when facing an increase in uncertainty (a real option value of waiting motive). For more on this alternative channel through which uncertainty propagates, see e.g. Bernanke (1983) and Pindyck (1988).

${ }^{32}$ It should be noted that modeling price rigidities with Calvo (1983) pricing rather than Rotemberg (1982) costs can have more sizeable effects on nominal variables such as inflation as documented elsewhere in the literature (see, e.g., Oh (2020)).
} 
nominal rigidities tempers the response of economic activity to TFP shocks. Similarly, the response of economic activity to TFP shocks is more muted with internal habits. In contrast, the inclusion of those same frictions in the model makes the economy more sensitive to micro-uncertainty. Monetary policy shocks require nominal rigidities, but otherwise their real effects are dampened by the addition of financial frictions and internal habits. Macrouncertainty and monetary policy uncertainty shocks are of second-order importance, yet nominal rigidities appear to be a modest amplifier, in particular of monetary policy uncertainty shocks, through the inverse "Oi-Hartman-Abel" effects discussed earlier.

Non-Scalability and Asymmetry of the Unconditional Impulse Responses The pruned third-order approximation of the nonlinear model solution allows for non-scalable and asymmetric responses to positive and negative shocks. To explore those properties, Figure 3 displays the response of output to \pm one- and two-standard deviation shocks. For the benchmark (M1), on average, the responses to negative and positive TFP shocks display patterns close to be scalable and symmetric. Still, two-standard deviation TFP shocks lead to a more pronounced hump-shaped response of output than one-standard deviation TFP shocks. The magnitude of the response also falls a touch short of doubling on impact when doubling the size of the TFP shock, and rises a bit less on impact in absolute value when doubling the size of a negative TFP shock than when doubling it for a positive one. In contrast, although the magnitude of the real effects caused by macro-uncertainty is the smallest, here we observe a substantial degree of asymmetry and robust evidence of nonscalability. Our findings show that larger macro-uncertainty shocks tend to produce more front-loaded real effects that dissipate faster than smaller ones.

For micro-uncertainty shocks, the presence of nonlinearities is also noticeable. On impact, a negative two-standard deviation micro-uncertainty shocks is more than $4 \%$ smaller in absolute value than a positive two-standard deviation one. For monetary policy shocks, the evidence of non-scalability and asymmetry is starker than that for other shocks with first-order effects (TFP and micro-uncertainty shocks). A negative (expansionary) twostandard deviation policy shock is, on average, almost $20 \%$ larger on impact in absolute value than a positive (contractionary) two-standard deviation shock. A two-standard deviation expansionary (negative) innovation boosts output on impact by about 2.16 times as much as a one-standard innovation does while a two-standard contractionary (positive) innovation lowers output only about 1.85 times as much as a one-standard innovation would. By contrast, we find that the responses to negative and positive monetary policy uncertainty shocks are close to being symmetric and scaling up. 
Figure 2. Unconditional Generalized Impulse Responses for Alternative Models
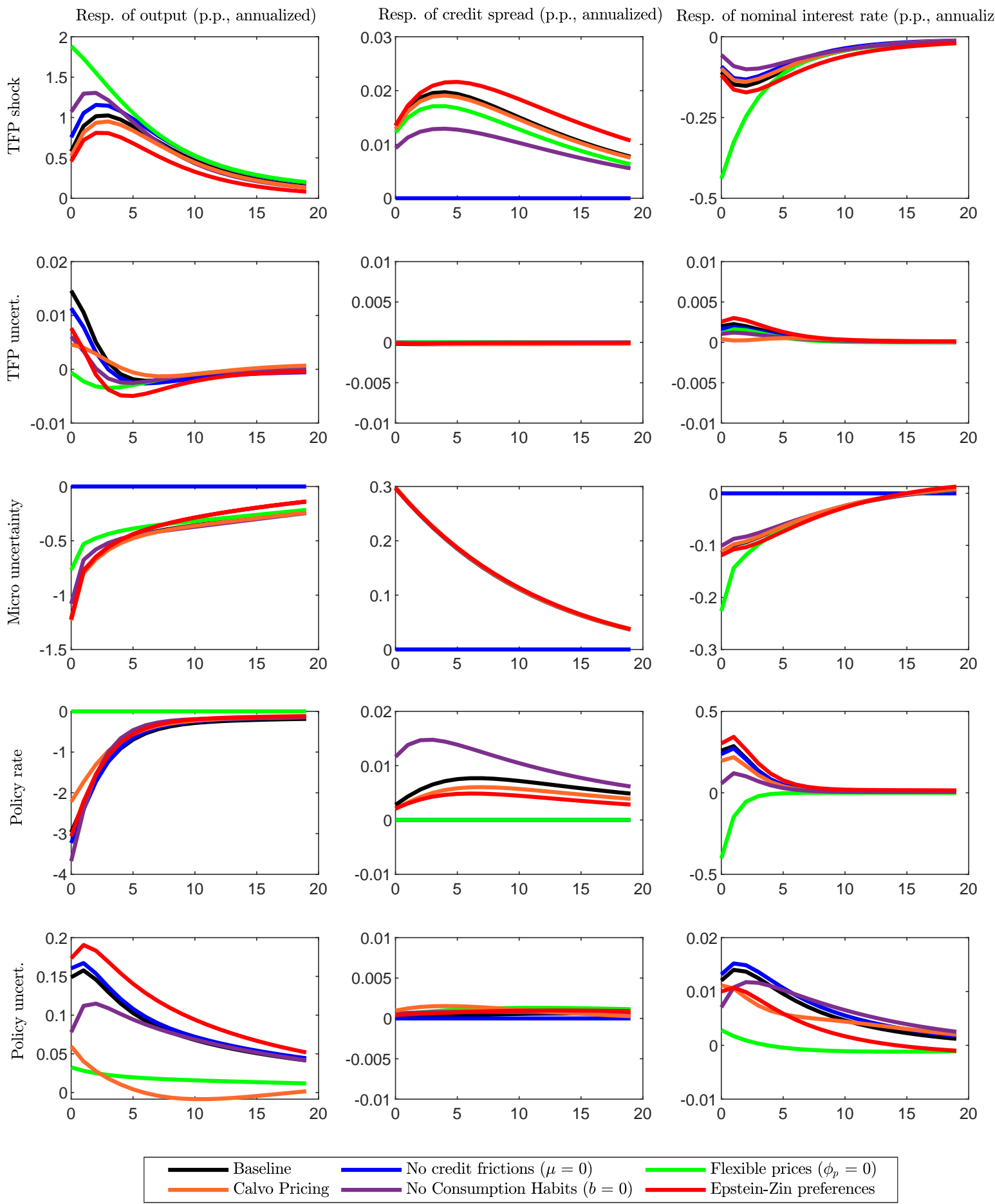

Flexible prices $\left(\phi_{p}=0\right)$

Epstein-Zin preferences

Note: The GIRFs are computed averaging across all initial conditions for each modeling specification. All responses are in percentage points, annualized. 
This suggests that, on average, the response of output to shocks does not always scale up or behave symmetrically, unlike what we would observe in a linear model. Most notably, these nonlinear features appear to be quantitatively most relevant for the propagation of monetary policy shocks. We interpret this as evidence that the nonlinearities in the model emerge also in part from the nominal rigidities present in the New Keynesian framework. ${ }^{33}$

\subsubsection{Conditional Impulse Responses}

Thus far, we have examined the average effect of shocks on key variables in our model. However, in general, shocks in nonlinear models are not path-independent. That is, the effect of the shocks could depend on the initial state of the economy. To get at this notion of conditional responses, we consider generalized impulse responses defined as:

$$
\operatorname{GIRF}_{y=y_{0}}\left(k, \mathbf{v}_{t}\right)=\int G I R F\left(k, \mathbf{v}_{t}, \mathbf{x}_{t-1}=\mathbf{x}\right) p\left(\mathbf{x} \mid y=y_{0}\right) d \mathbf{x}
$$

where $k$ is again shorthand for the horizon of interest, $\mathbf{v}_{t}$ refers to the shock innovations, and $p\left(\mathbf{x} \mid y=y_{0}\right)$ is the conditional density of the vector of states $\mathbf{x}$ implied by the model when the endogenous variable $y$ is initially at $y_{0}$. That is, given that a variable $y$ is initially at $y_{0}$, we average over the possible states consistent with this initial condition.

In the benchmark model $(M 1)$, the expected costs of monitoring defaulting entrepreneurs are priced into the credit spreads that lenders charge on their loans. Hence, credit spreads reflect the extent to which credit is distorted and entrepreneur risk (or financial risk) is present and, thus, instances where the credit spread is high are thought to coincide with episodes when financial conditions are poor. To show the interaction between financial conditions and shocks, we consider a generalized impulse response analysis in which the initial conditions correspond to states where the credit spread level is either high or low. ${ }^{34}$

We also explore the initial conditions on two other endogenous variables related to financial conditions. First, the endogenous equity ratio which together with the exogenous micro-uncertainty are the two components that determine the credit spread in (14). When the equity ratio is high, the strength of the entrepreneurs' balance sheet acts as a financial buffer since then entrepreneurs are less leveraged on external borrowed funds. Second, the

\footnotetext{
${ }^{33}$ On this point, see e.g. Balke et al. (2017b) (Figure 7) which explores conditional output responses in the benchmark model ( $M 1)$, abstracting from financial frictions $(M 6)$, and under flexible prices $(M 7)$.

${ }^{34}$ Balke (2000) also examines, in the context of a threshold VAR, whether the effects of shocks depend on current credit conditions. More recently, the amplifying role of credit frictions for the effects of uncertainty shocks has been explored empirically by Alessandri and Mumtaz (2019) and L'huissier and Tripier (2019). For the asymmetric effects of shocks (monetary policy shocks), see e.g. Barnichon and Matthes (2018).
} 
Figure 3. Generalized Impulse Response of Output to Alternative Shock Sizes and Directions
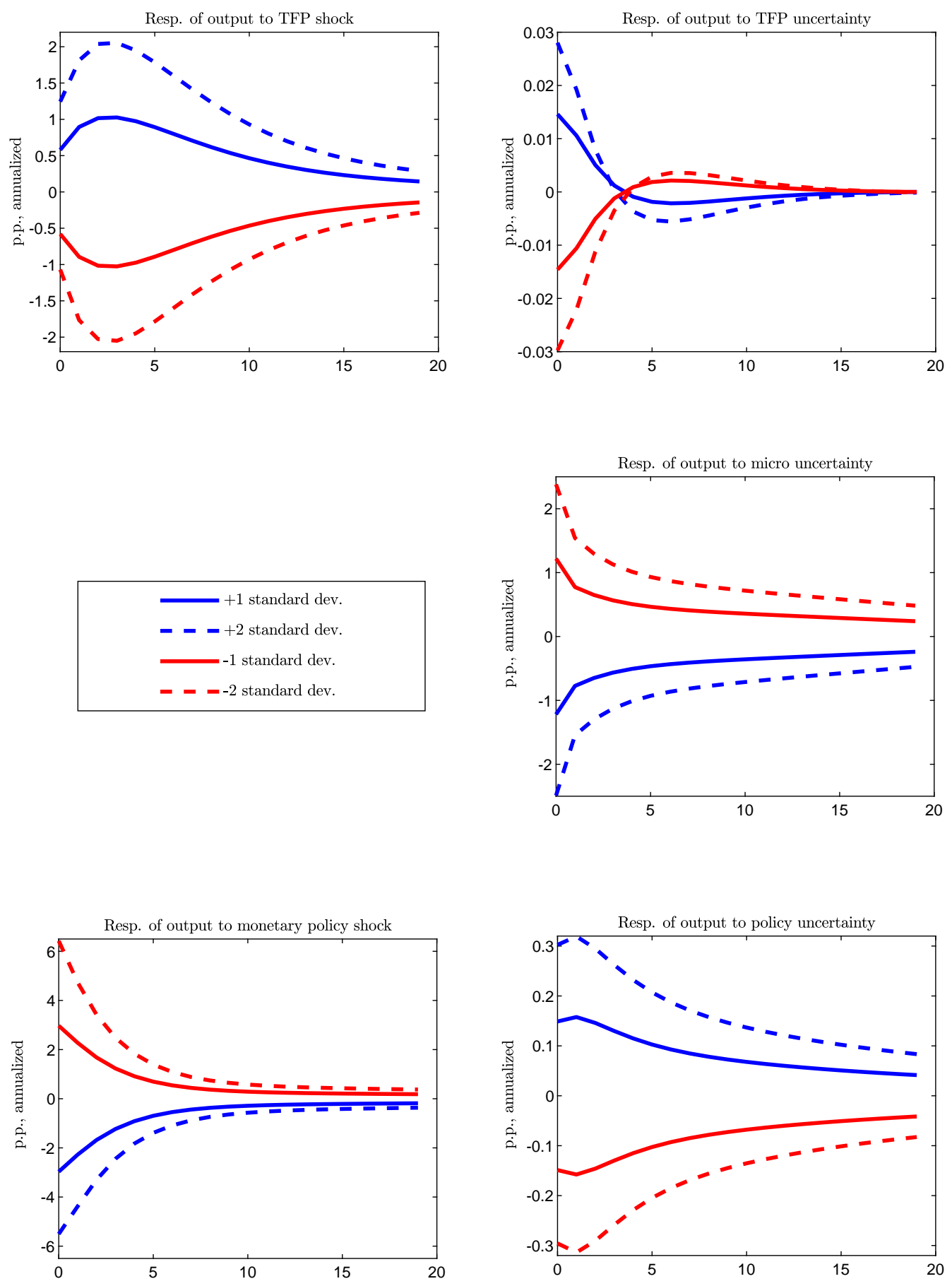

Note: The GIRFs are computed averaging across all initial conditions under the baseline model. All responses are in percentage points, annualized. 
nominal interest rate which together with the credit spread determines the cost of borrowing for entrepreneurs in (14). Hence, when the nominal interest rate is elevated, borrowing costs are high and financial conditions worsen, ceteris paribus.

The Amplification Effect of Financial Conditions Figure 4 displays the response of output, the credit spread, and the nominal interest rate to the shocks with first-order effects (TFP, micro-uncertainty, and monetary policy shocks) under the benchmark model (M1), but conditional on the credit spread being either high or low. Specifically, we define high spread initial states as states where the credit spread is roughly at the $95^{\text {th }}$ percentile of its unconditional distribution and low spread initial states as states where the credit spread is at its $5^{\text {th }}$ percentile. ${ }^{35}$ We observe that the effect of both macro-uncertainty and monetary policy uncertainty shocks does not depend on current credit conditions. The responses are virtually identical and tiny regardless of whether the spread is initially high or low and for that reason we do not report them in Figure $4 .^{36}$

In Figure 4, the output response to a positive TFP shock retains its hump-shaped form regardless of whether credit spreads are high or low, but, at its peak four quarters into the future, the impact is almost $10 \%$ higher when financial conditions are benign (low spread) than when they are poor (high spreads). The contractionary effect of an increase in microuncertainty when the spread is initially high is about $35 \%$ larger than when the spread is initially low. Similarly, the contractionary effect on output of a positive monetary policy shock is about $20 \%$ more severe on impact when financial conditions are poor (high spreads).

The increase in the credit spread in response to TFP, monetary policy, and microuncertainty shocks is larger when the spread is already high. This is particularly striking for micro-uncertainty shocks - the effect on the credit spread of a positive micro-uncertainty shock is about $80 \%$ larger on impact when the credit spread is initially high as opposed to when the spread is initially small. Moreover, we find that the effect of a positive monetary policy shock on the credit spread is smaller than that of a TFP shock and at least one order

\footnotetext{
${ }^{35}$ For impulse responses conditional on variable $y$ being at its $\iota$-th percentile, $y\left(\iota^{\text {th }}\right)$, we average the responses for initial conditions corresponding to realizations from the unconditional distribution where variable $y \in\left[y(\iota-.3)^{t h}, y(\iota+.3)^{t h}\right]$. Given our 20,000 draws of the unconditional distribution, we therefore end up averaging over 121 initial conditions.

${ }^{36}$ Cacciatore and Ravenna (2020) show that second-moment shocks in general propagate linearly in a pruned third-order approximation model solution, altough the unpruned solution could allow for some statedependence. In our model, the loan contracting problem implies sizeable first-order effects from a secondmoment shock (micro-uncertainty). Micro-uncertainty can, therefore, display significant path-dependence even if macro-uncertainty and monetary policy uncertainty shocks behave largely as predicated by Cacciatore and Ravenna (2020). Balke et al. (2017b) (Figures 2 to 5) show some further evidence of this looking at the tails of the distribution of the endogenous credit spread and of the exogenous micro-uncertainty.
} 
of magnitude lower than that of a micro-uncertainty shock.

These results suggest that, if current credit conditions are poor (high spread), then the effect of a supply-side (TFP) shocks tends to be dampened while the effect of contractionary monetary or financial shocks (a positive monetary policy shock or a positive microuncertainty shock) is substantially magnified. Micro-uncertainty works primarily through its impact on the credit spread, while the amplification of monetary policy shocks has quite small effects on the credit spread and operates primarily through raising the financial intermediaries' cost of attracting household savings through deposits. Simply put, what happens is that the increase in the nominal interest rate caused by the same monetary policy shock leads to higher overall external borrowing costs for the entrepreneurs when the credit spread is initially high than if financial conditions were good (low spread).

Figure 5.A and Figure 5.B display the response of the same variables (output, credit spread, and nominal interest rate) to the three shocks with first-order effects (TFP, microuncertainty, and monetary policy shocks) conditional on whether the credit spread, the equity ratio, and the nominal interest rate are initially high or low. The generalized impulse responses conditional on the credit spread and the equity ratio are plotted in Figure 5.A while the responses conditional on the credit spread and the nominal interest rate are compared in Figure 5.B. We continue to take high initial states to be where each of the variables is roughly at the $95^{\text {th }}$ percentile of its unconditional distribution and low initial values when roughly at the $5^{\text {th }}$ percentile.

We find in Figure 5.A that a high equity ratio can act as a financial buffer. The response of output to monetary policy shocks shows that a stronger balance sheet position of the entrepreneurs means the economy is in a better position to absorb the impact from a positive (contractionary) monetary policy shock and limit the resulting output drag. Indeed, we find that the output decline is about $10 \%$ smaller on impact in response to a positive monetary policy shock if the equity ratio is high than if it is low, while simultaneously, the increase in the credit spread when the equity ratio is high is fairly similar to the increase observed when the credit spread itself is initially low.

Even more strikingly, we show in Figure 5.B that positive (contractionary) monetary policy shocks have much larger effects when they are conditional on interest rates than when conditional on credit spreads (whether high or low). Moreover, the response of output is about $15 \%$ lower and the credit spread increases somewhat if initial interest rates are low rather than high. This suggests that the demand for capital implied by (14) tends to be more elastic when interest rates are initially high than when it is initially low.

Moreover, the effect of TFP and micro-uncertainty shocks on the credit spread is more 
compressed when comparing initial conditions where the nominal interest rates are initially high and low, than when spreads are initially high and low. Also, the transmission of TFP shocks is perhaps most distinctly affected by whether tight financial conditions arise from high spreads or high nominal interest rates. As we see in Figure 5.B, on impact, the output boost is more than $20 \%$ lower when nominal interest rates are initially low than when credit spreads are initially low, but at its peak in the fourth quarter output is about $4.5 \%$ higher.

Finally, to explore the contribution of each shock to the credit spread, Figure 6 displays the scatter plots implied by the unconditional model-implied distribution of the credit spread against each of the five shocks separately (TFP, monetary policy, macro-uncertainty, policy uncertainty, and micro-uncertainty). ${ }^{37}$ These scatter plots show that there is a strong relationship between the exogenous micro-uncertainty and the endogenous credit spread. The correlation coefficient between exogenous micro-uncertainty and the endogenous credit spread is 0.84 . Interestingly, this relationship also appears to be nonlinear to some extent. In contrast, none of the other shocks appear to have a strong relationship with the credit spread. This indicates that the credit spread fluctuations largely arise from the micro-uncertainty shock and to a much lesser extent from the endogenous response to other shocks. ${ }^{38}$

\section{Business cycle fluctuations and their relation with time-varying own uncertainty.}

While we have established earlier that the response of key variables varies conditional on current financial conditions, the responses to shocks are also conditional on their own uncertainty. Figure 7 displays the responses of output, the credit spread, and the nominal interest rate to TFP, micro-uncertainty, and monetary policy shocks conditional on their own uncertainty being high $\left(95^{\text {th }}\right.$ percentile) or low ( $5^{\text {th }}$ percentile). For comparison, we also include the responses when credit spreads are initially high or low. ${ }^{39}$

We observe that, for micro-uncertainty, the responses of output to shocks conditional on the level of micro-uncertainty are very similar to the output responses conditional on the initial credit spread. Given the relatively strong relationship between realizations of microuncertainty and the credit spread shown previously in Figure 6, this is to be expected. We

\footnotetext{
${ }^{37}$ Balke et al. (2017b) (Figures 12 to 13 ) provide the joint distribution of the credit spread against other economically-relevant variables of the model as well.

${ }^{38}$ The correlations between the spread and $\left\{a_{t}, m_{t}, \widehat{\sigma}_{a, t}, \widehat{\sigma}_{m, t}\right\}$ are $\{0.07,0.00,0.00,0.00\}$, respectively. These shocks affect the numerator and denominator of the equity ratio roughly in a similar proportion. As a result, this elicits only a modest endogenous response of the credit spread. Consequently, exogenous changes in micro-uncertainty end up being the dominant force on the spread.

${ }^{39}$ The responses of output, the credit spread, and the nominal interest rate to TFP, micro-uncertainty, and monetary policy shocks conditional on other uncertainty types except their own are very similar whether those other uncertainty types are high $\left(95^{\text {th }}\right.$ percentile) or low $\left(5^{\text {th }}\right.$ percentile). Further details on that can be found in Balke et al. (2017b) (see, e.g., Figures 1, 6, and 10).
} 
Figure 4. Generalized Impulse Response of Output, Credit Spread, and Nominal Interest Rate to Shocks Conditional on the Value of the Credit Spread
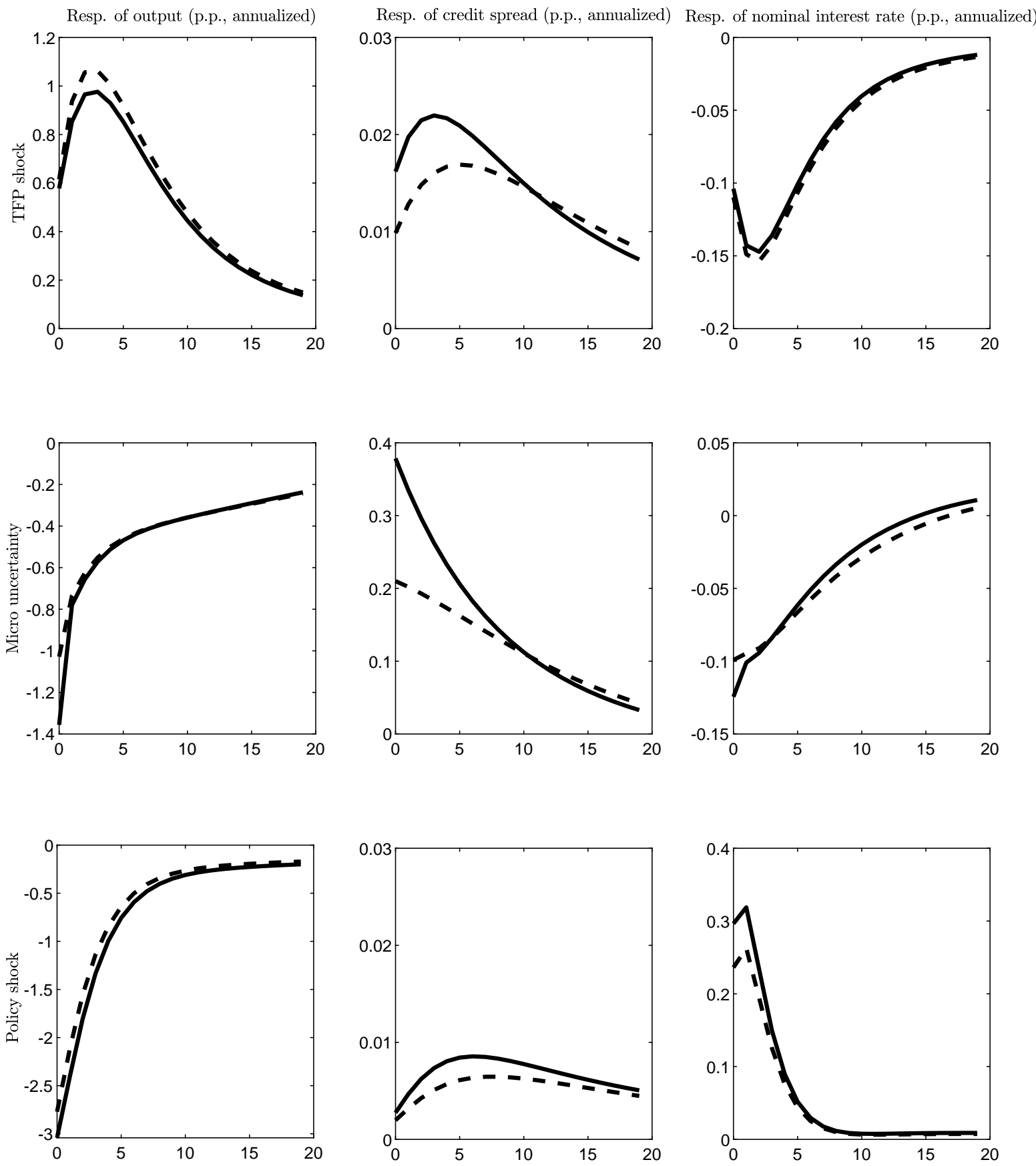

\section{At percentile of:}

$95 \%$ credit spread $-2-5 \%$ credit spread

Note: The GIRFs are computed averaging conditional on the level of the credit spread under the baseline model. All responses are in percentage points, annualized. 
Figure 5.A Generalized Impulse Response of Output, Credit Spread, and Nominal Interest Rate to Shocks Conditional on the Value of the Credit Spread and the Equity Ratio
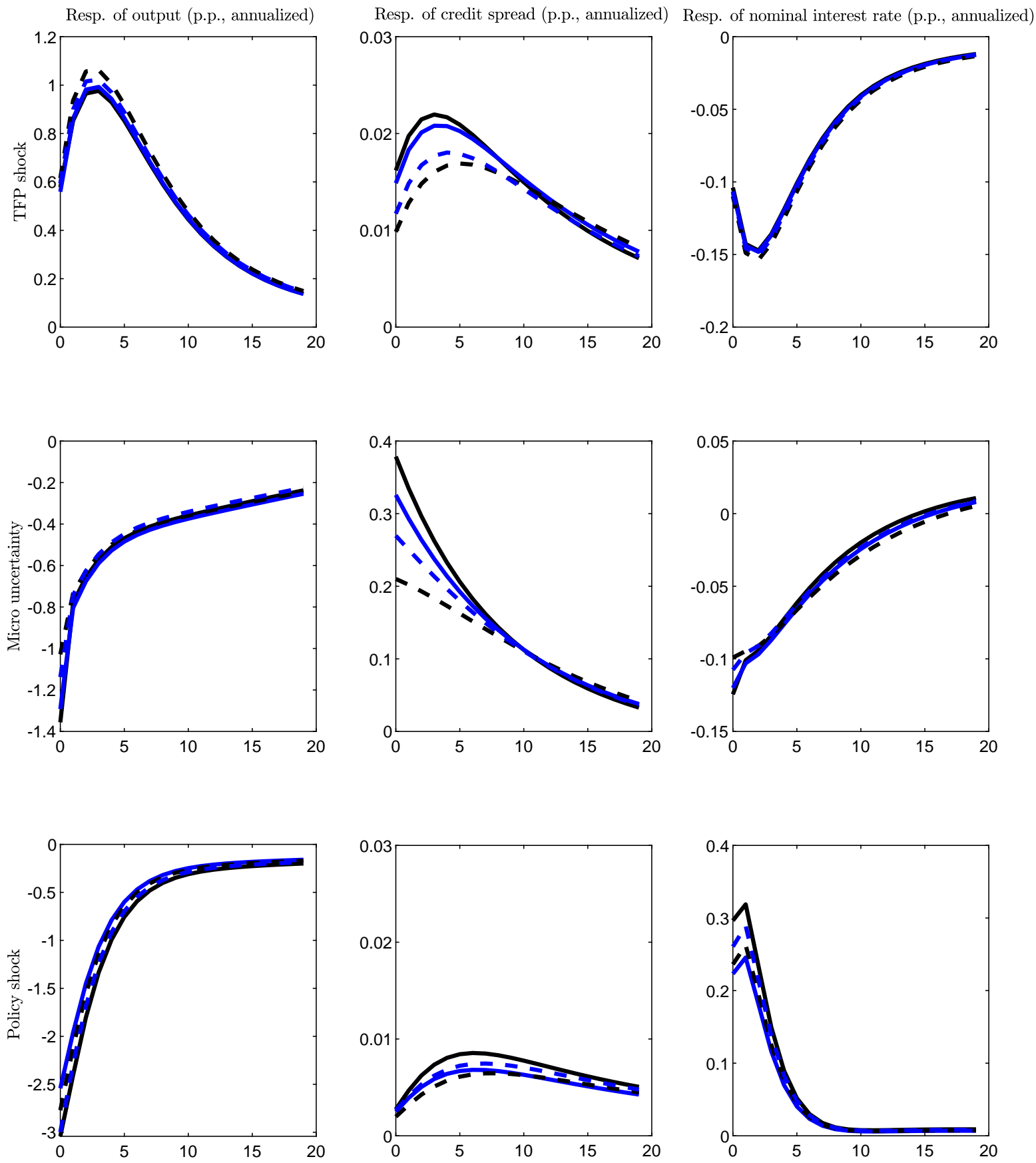

At percentile of:

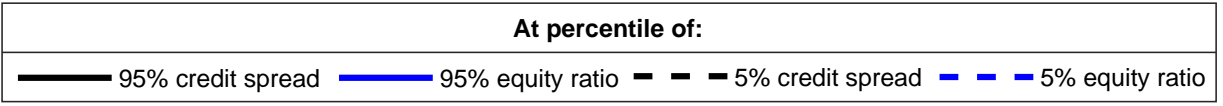

Note: The GIRFs are computed averaging conditional on the level of the credit spread and on the level of the equity ratio under the baseline model. All responses are in percentage points, annualized. 
Figure 5.B Generalized Impulse Response of Output, Credit Spread, and Nominal Interest Rate

to Shocks Conditional on the Value of the Credit Spread and the Nominal Interest Rate
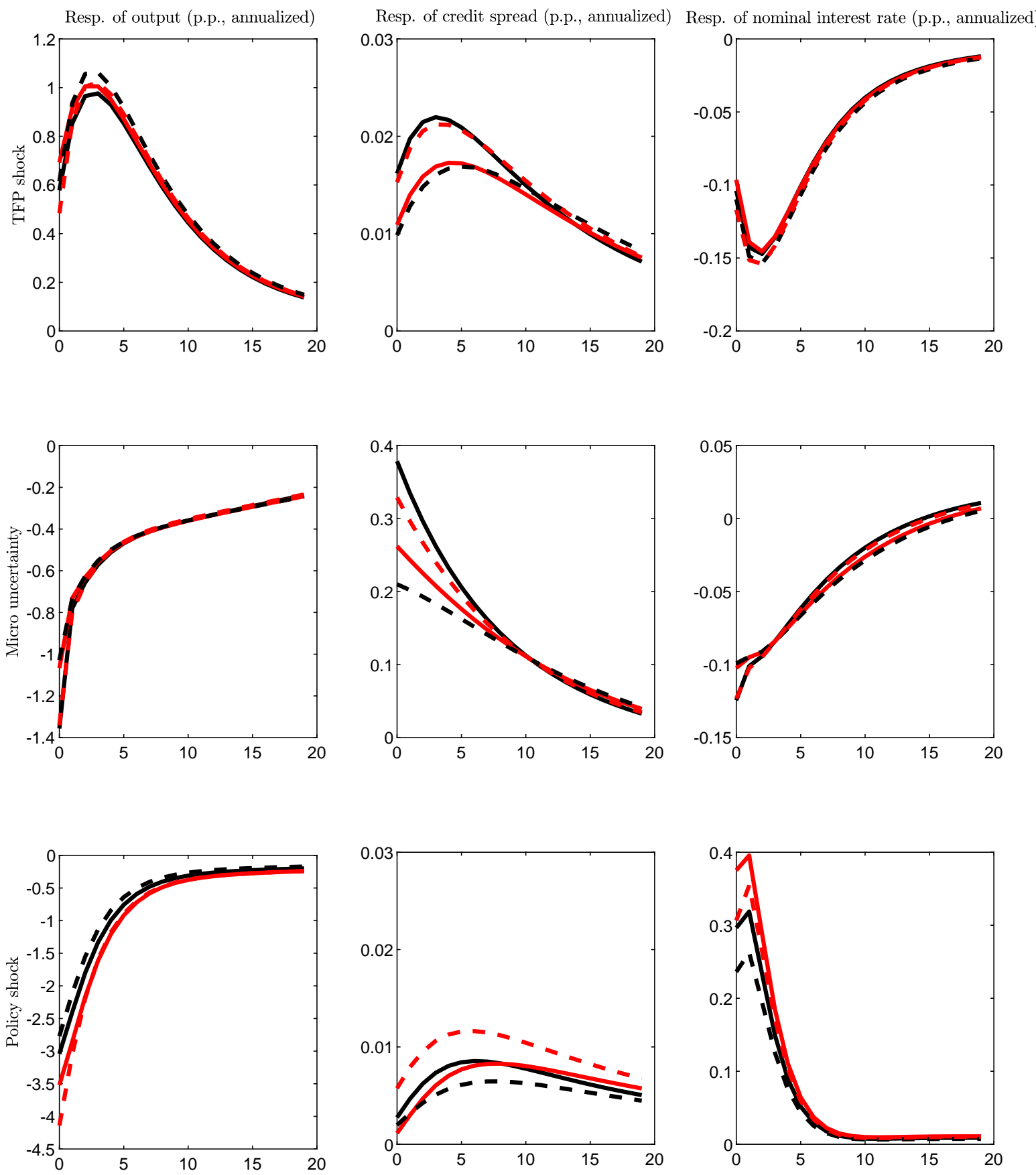

At percentile of:

$95 \%$ credit spread

$95 \%$ nominal interest rate $-25 \%$ credit spread $-2-5 \%$ nominal interest rate

Note: The GIRFs are computed averaging conditional on the level of the credit spread and on the level of the nominal interest rate under the baseline model. All responses are in percentage points, annualized. 
Figure 6. Scatterplot of the Unconditional Distribution for the Baseline Model
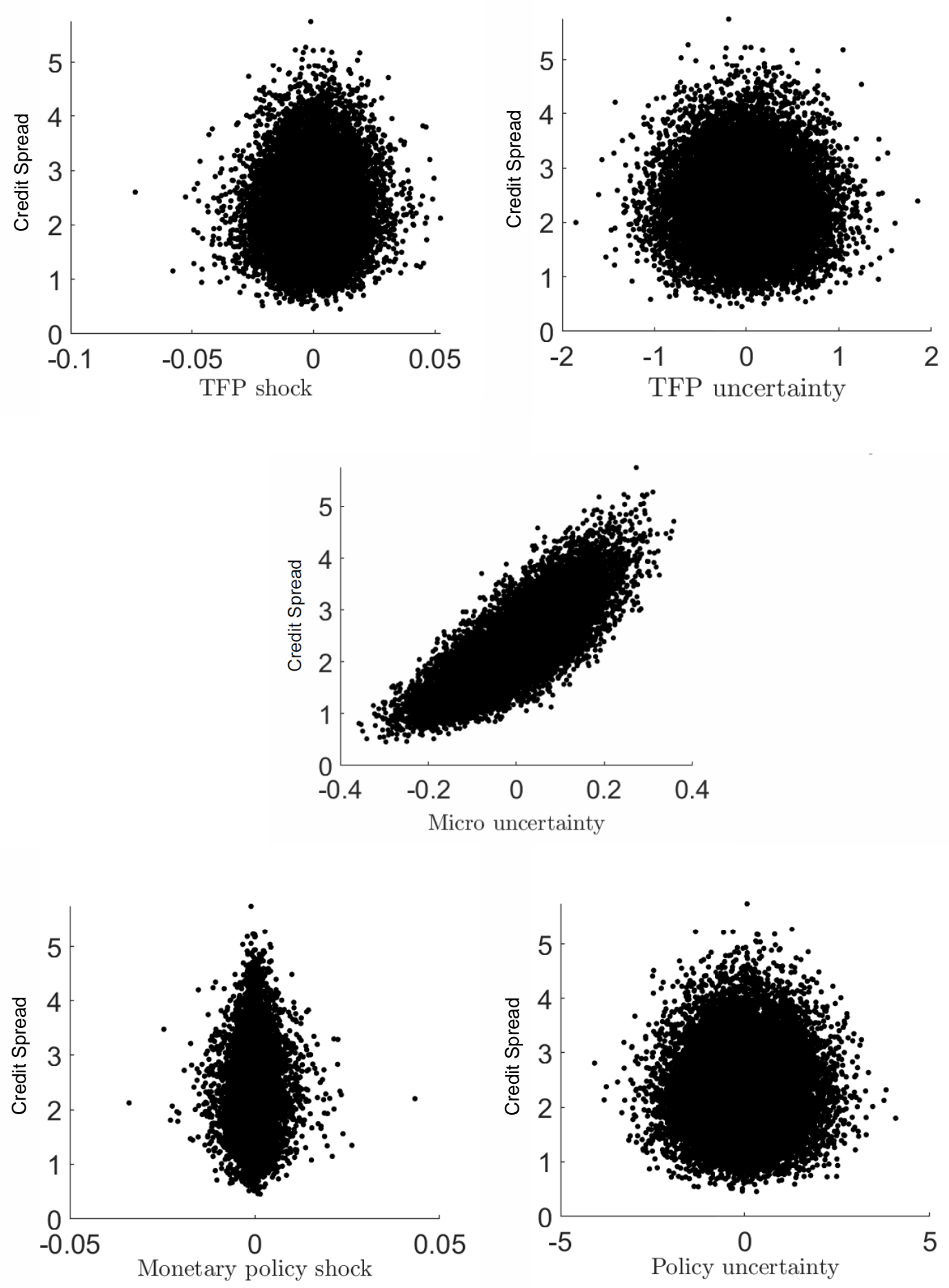

Note: The scatterplot displays the simulated data of the credit spread and each one of the shock types under the baseline model. All responses are in percentage points, annualized. 
also find in Figure 7 that the output response to TFP shocks and monetary policy shocks is larger when their own uncertainty is high, primarily for the obvious reason that a high level of their own uncertainty means the size of the shocks is larger too.

Furthermore, the range of TFP and monetary policy effects between low and high levels of their own uncertainty is ostensibly higher than the range we observe between low and high credit spreads. In fact, the economic contraction resulting from a positive monetary policy shock when monetary policy uncertainty is initially high almost triples that which we observe when financial conditions are poor (as measured by high spreads). This large output sensitivity to monetary policy shocks when their own uncertainty is time-varying is what ultimately explains the large fall in business cycle volatility that we detect in Table 3 when we remove monetary policy uncertainty from the benchmark model (M5 vs. M1).

\section{Concluding Remarks}

In this paper we examine the interaction between uncertainty (stochastic volatility) and credit frictions arising from asymmetric information and costly monitoring through the lens of a mainstream New Keynesian model. We estimate the key structural parameters by the Simulated Method of Moments (SMM) relying on a pruned third-order approximation to the model solution, calculate various business cycle moments, and conduct an extensive analysis of the nonlinearities of the model in the propagation of shocks through impulse responses.

Notably, we find that contractionary monetary policy shocks have a significantly lower average response than expansionary shocks of equal size (when compared in absolute value). Furthermore, those differences widen with larger monetary policy shock realizations at the tails of the distribution. In other words, the transmission mechanism of monetary policy is such that monetary policy shocks are, on average, more effective at providing accommodation than at removing it. The asymmetric and non-scalability features on the responses of monetary policy shocks and even of TFP shocks are, to be sure, sensitive to the degree and type of nominal rigidities built into the model as well as to the presence of credit frictions.

Similar to Christiano et al. (2014) and Cesa-Bianchi and Fernández-Corugedo (2018), we observe that second-moment financial risk or micro-uncertainty shocks have first-order effects of comparable magnitude to first-moment shocks to TFP or monetary policy even when the degree of credit frictions is not particularly severe. However, we also find that the interaction between micro-uncertainty and credit frictions goes beyond just the amplification of these micro-uncertainty shocks. Unlike the previous literature, we show that conditioning 
Figure 7. Generalized Impulse Response of Output, Credit Spread, and Interest Rate to Shocks Conditional on the Value of the Credit Spread and Own Uncertainty Type
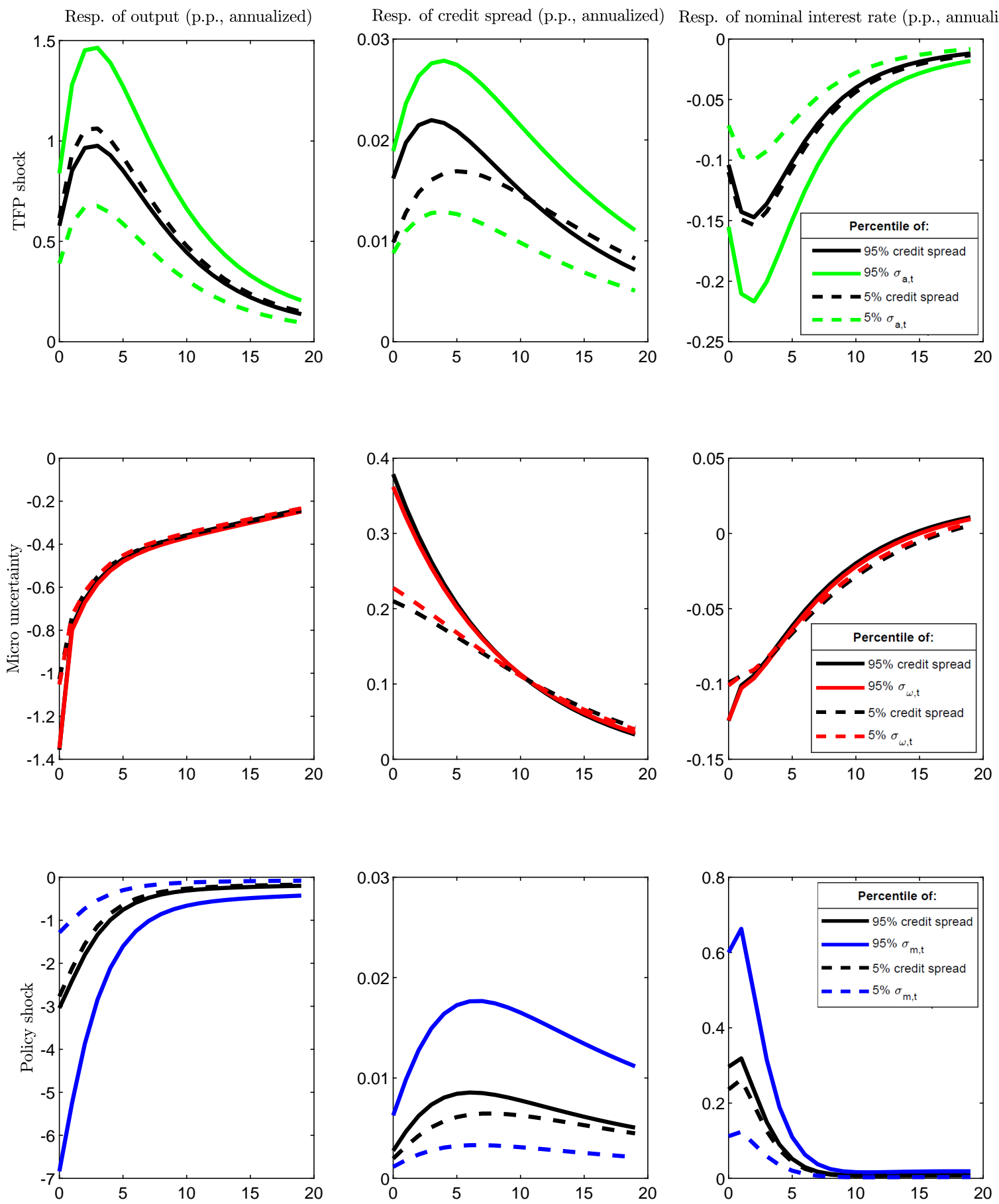

Note: The GIRFs are computed averaging conditional on the level of the credit spread and on the level of the own uncertainty type under the baseline model. All responses are in percentage points, annualized. 
on financial conditions (credit spreads) - or on micro-uncertainty to the extent that it is the most significant driver of credit spreads - has a significant qualitative and quantitative impact on the endogenous responses of other shocks with first-order effects in the model.

We find that the contractionary effect of an increase in micro-uncertainty tends to be larger when the current credit spread is high (indicating a deteriorating credit environment). Moreover, poor credit conditions temper the economic boost from a positive TFP shock while exacerbate the drag on economic activity from a contractionary monetary policy shock. Hence, we see that the transmission mechanism of monetary policy is impacted as the propagation of monetary policy shocks is shown to depend on the level of micro-uncertainty and, more broadly, on the prevailing financial conditions. The responses of shocks with firstorder effects also deteriorate whenever balance sheets are impaired and with tight credit conditions resulting from high nominal interest rates or elevated credit spreads.

Finally, we find that the interaction of credit frictions with macro-uncertainty and monetary policy uncertainty produces relatively small effects. The resulting small boost to economic activity partly reflects the sort of inverse "Oi-Hartman-Abel" effects identified in Born and Pfeifer (2014). Monetary policy uncertainty in particular, due to the output sensitivity to monetary shocks in the presence of nominal rigidities, is shown to account for a sizeable fraction of the business cycle volatility explained by the model.

We leave for future research incorporating longer-term financial contracts, particularly loan contracts set in nominal terms, into the specification. Furthermore, in the model, net worth is largely affected by the price of capital; the size of fluctuations in the price of capital depends, in turn, largely on the adjustment costs on capital. Adding a stronger asset price channel might generate greater fluctuations in net worth and larger endogenous movements in the credit spread. We leave that and other avenues of research on the functioning of credit markets in general equilibrium for future research as well. ${ }^{40}$

\footnotetext{
${ }^{40}$ There may be also other non-financial frictions that we are not considering in our benchmark that could be important to explore in the future. If there were other frictions that interact with uncertainty (e.g., firm hiring decisions or firm-specific adjustment costs), then uncertainty can also have an additional impact independent of credit frictions.
} 


\section{Bibliography}

Abel, A. B. (1983). Optimal Investment Under Uncertainty. American Economic Review 73(1), 228-233. https://www.jstor.org/stable/1803942.

Alessandri, P. and H. Mumtaz (2019). Financial Regimes and Uncertainty Shocks. Journal of Monetary Economics 101, 31-46. https://doi.org/10.1016/j.jmoneco.2018.05.001.

Alexopoulos, M. and J. Cohen (2009). Uncertain Times, Uncertain Measures. University of Toronto, Department of Economics, Working paper no. 352.

Andreasen, M. M., J. Fernández-Villaverde, and J. F. Rubio-Ramírez (2018). The Pruned State-Space System for Non-Linear DSGE Models: Theory and Empirical Applications. The Review of Economic Studies 85(1), 1-49. https://doi.org/10.1093/restud/rdx037.

Ascari, G. and A. M. Sbordone (2014). The Macroeconomics of Trend Inflation. Journal of Economic Literature 52(3), 679-739. https://doi.org/10.1257/jel.52.3.679.

Balke, N., E. Martínez-García, and Z. Zeng (2017a). In No Uncertain Terms: The Effect of Uncertainty on Credit Frictions and Monetary Policy. Federal Reserve Bank of Dallas Globalization and Monetary Policy Institute Working Paper No. 317. June 2017 (Revised: January 2021). https://doi.org/10.24149/gwp317r2.

Balke, N., E. Martínez-García, and Z. Zeng (2017b). In No Uncertain Terms: The Effect of Uncertainty on Credit Frictions and Monetary Policy - Supplementary Materials and Additional Results. Federal Reserve Bank of Dallas Globalization and Monetary Policy Institute Working Paper No. 317a. June 2017 (Revised: January 2021). https://doi.org/10.24149/gwp317suppr2.

Balke, N. S. (2000). Credit and Economic Activity: Credit Regimes and Nonlinear Propagation of Shocks. The Review of Economics and Statistics 82(2), 344-349. https://doi.org/10.1162/rest.2000.82.2.344.

Barnichon, R. and C. Matthes (2018). Functional Approximation of Impulse Responses. Journal of Monetary Economics 99, 41-55. https://doi.org/10.1016/j.jmoneco.2018.04.013.

Basu, S. (1996). Procyclical Productivity: Increasing Returns or Cyclical Utilization? Quarterly Journal of Economics 111(3), 719-51. https://doi.org/10.2307/2946670.

Basu, S. and B. Bundick (2017). Uncertainty Shocks in a Model of Effective Demand. Econometrica 85(3), 937-958. https://doi.org/10.3982/ECTA13960. 
Ben-Haim, Y., M. Demertzis, and J. W. Van den End (2018). Evaluating Monetary Policy Rules Under Fundamental Uncertainty: An Info-Gap Approach. Economic Modelling 73, 55-70. https://doi.org/10.1016/j.econmod.2018.03.004.

Bernanke, B. S. (1983). Irreversibility, Uncertainty, and Cyclical Investment. The Quarterly Journal of Economics 98(1), 85-106. https://doi.org/10.2307/1885568.

Bernanke, B. S. and M. Gertler (1989). Agency Costs, Net Worth, and Business Fluctuations. American Economic Review 79(1), 14-31. https://www.jstor.org/stable/1804770.

Bernanke, B. S., M. Gertler, and S. Gilchrist (1996). The Financial Accelerator and the Flight to Quality. The Review of Economics and Statistics 78(1), 1-15. https://doi.org/10.2307/2109844.

Bernanke, B. S., M. L. Gertler, and S. Gilchrist (1999). The Financial Accelerator in a Quantitative Business Cycle Framework. In J. B. Taylor and M. Woodford (Eds.), Handbook of Macroeconomics, vol. 1, Chapter 21, pp. 1341-1393. Elsevier Science B.V. https://doi.org/10.1016/s1574-0048(99)10034-x.

Bloom, N. (2009). The Impact of Uncertainty Shocks. Econometrica 77(3), 623-685. https://doi.org/10.3982/ECTA6248.

Bloom, N., M. Floetotto, N. Jaimovich, I. Saporta-Eksten, and S. J. Terry (2018). Really Uncertain Business Cycles. Econometrica 86(3), 1031-1065. https://doi.org/10.3982/ECTA10927.

Boldrin, M., L. J. Christiano, and J. D. M. Fisher (2001). Habit Persistence, Asset Returns, and the Business Cycle. American Economic Review 91(1), 149-166. https://doi.org/10.1257/aer.91.1.149.

Born, B. and J. Pfeifer (2014). Policy Risk and the Business Cycle. Journal of Monetary Economics 68(68-85). https://doi.org/10.1016/j.jmoneco.2014.07.012.

Caballero, R. J. (1990). Consumption Puzzles and Precautionary Savings. Journal of Monetary Economics 25, 113-136. https://doi.org/10.1016/0304-3932(90)90048-9.

Cacciatore, M. and F. Ravenna (2020). Uncertainty, Wages, and the Business Cycle. CEPR Discussion Paper No. DP14715. https://ssrn.com/abstract=3594350.

Calvo, G. A. (1983). Staggered Prices in a Utility-Maximizing Framework. Journal of Monetary Economics 12(3), 383-398. https://doi.org/10.1016/0304-3932(83)90060-0. 
Carlstrom, C. T. and T. S. Fuerst (1997). Agency Costs, Net Worth, and Business Fluctuations: A Computable General Equilibrium Analysis. American Economic Review 87(5), 893-910. https://www.jstor.org/stable/2951331.

Carlstrom, C. T., T. S. Fuerst, and M. Paustian (2010). Optimal Monetary Policy in a Model with Agency Costs. Journal of Money, Credit and Banking 42(s1), 37-70. https://doi.org/10.1111/j.1538-4616.2010.00329.x.

Carroll, C. D. and M. S. Kimball (2008). Precautionary Saving and Precautionary Wealth. In S. N. Durlauf and E. Blume, Lawrence (Eds.), The New Palgrave Dictionary of Economics. Basingstoke: Palgrave Macmillan. https://doi.org/10.1057/ 978-1-349-95121-5_2079-1.

Cesa-Bianchi, A. and E. Fernández-Corugedo (2018). Uncertainty, Financial Frictions, and Nominal Rigidities: A Quantiative Investigation. Journal of Money, Credit and Banking 50(4), 603-636. https://doi.org/10.1111/jmcb.12505.

Christiano, L. J., M. Eichenbaum, and C. L. Evans (2005). Nominal Rigidities and the Dynamic Effects of a Shock to Monetary Policy. Journal of Political Economy 113(1), 1-45. https://doi.org/10.1086/426038.

Christiano, L. J., R. Motto, and M. Rostagno (2014). Risk Shocks. American Economic Review 104(1), 27-65. https://www.doi.org/10.1257/aer.104.1.27.

Chugh, S. K. (2016). Firm Risk and Leverage-Based Business Cycles. Review of Economic Dynamics 20, 111-131. https://doi.org/10.1016/j.red.2016.02.001.

Cohen-Cole, E. and E. Martínez-García (2010). The Balance Sheet Channel. In R. A. Alfaro (Ed.), Financial Stability, Monetary Policy, and Central Banking, Central Banking, Analysis, and Economic Policies, Chapter 9, pp. 255-297. Santiago, Chile: Central Bank of Chile. https://bit.ly/3lsqGHZ. A working paper version can be found here: https://doi.org/10.2139/ssrn.2365048.

Coulter, J. and E. Martínez-García (2020). Policymakers' Response to COVID-19 Can Draw on Great Recession Lessons. Dallas Fed Economics Blog. July 07, 2020. https://www.dallasfed.org/research/economics/2020/0707.aspx.

Córdoba, J.-C. and M. Ripoll (2004). Credit Cycle Redux. International Economic Review 45(4), 1011-1046. https://doi.org/10.1111/j.0020-6598.2004.00296.x.

de Blas, B. and M. Malmierca (2020). Financial Frictions and Stabilization Policies. Economic Modelling 89, 166-188. https://doi.org/10.1016/j.econmod.2019.10.019. 
Dib, A., C. Mendicino, and Y. Zhang (2013). Price-Level Targeting Rules and Financial Shocks: The Case of Canada. Economic Modelling 30, 941-953. https://doi.org/10.1016/j.econmod.2012.09.038.

Dorofeenko, V., G. S. Lee, and K. D. Salyer (2008). Time-Varying Uncertainty and the Credit Channel. Bulletin of Economic Research 60(4), 375-403. https://doi.org/10.1111/j.1467-8586.2008.00284.x.

Epstein, L. G. and S. E. Zin (1989). Substitution, Risk Aversion, and the Temporal Behavior of Consumption and Asset Returns: A Theoretical Framework. Econometrica 57(4), 937-969. https://doi.org/10.2307/1913778.

Faia, E. and T. Monacelli (2007). Optimal Interest Rate Rules, Asset Prices, and Credit Frictions. Journal of Economic Dynamics and Control 31(10), 3228-3254. https://doi.org/10.1016/j.jedc.2006.11.006.

Fernández-Villaverde, J. (2010). The Econometrics of DSGE Models. SERIEs 1(1-2), 349. https://doi.org/10.1007/s13209-009-0014-7.

Fernández-Villaverde, J., P. Guerrón-Quintana, and J. F. Rubio-Ramírez (2010). Fortune or Virtue: Time-Variant Volatilities Versus Parameter Drifting in U.S. Data. NBER Working Paper no. 15928. https://doi.org/10.3386/w15928.

Fernández-Villaverde, J., P. Guerrón-Quintana, J. F. Rubio-Ramírez, and M. Uribe (2011). Risk Matters: The Real Effects of Volatility Shocks. American Economic Review 101(6), 2530-2561. https://doi.org/10.1257/aer.101.6.2530.

Fernández-Villaverde, J. and J. F. Rubio-Ramírez (2005). Estimating Dynamic Equilibrium Economies: Linear Versus Nonlinear Likelihood. Journal of Applied Econometrics 20(7), 891-910. https://doi.org/10.1002/jae.814.

Fernández-Villaverde, J. and J. F. Rubio-Ramírez (2006). Solving DSGE Models with Perturbation Methods and a Change of Variables. Journal of Economic Dynamics and Control 30(12), 2509-2531. https://doi.org/10.1016/j.jedc.2005.07.009.

Gale, D. and M. F. Hellwig (1985). Incentive-Compatible Debt Contracts: The One-Period Problem. Review of Economic Studies 52(4), 647-664. https://doi.org/10.2307/2297737.

Gerke, R., M. Jonsson, M. Kliem, M. Kolasa, P. Lafourcade, A. Locarno, K. Makarski, and P. McAdam (2013). Assessing Macro-Financial Linkages: A Model Comparison Exercise. Economic Modelling 31, 253-264. 
https://doi.org/10.1016/j.econmod.2012.10.019.

Gilchrist, S., J. W. Sim, and E. Zakrajsek (2013). Misallocation and Financial Market Frictions: Some Direct Evidence from the Dispersion in Borrowing Costs. Review of Economic Dynamics 16(1), 159-176. https://doi.org/10.1016/j.red.2012.11.001.

Gomes, J. F., A. Yaron, and L. Zhang (2003). Asset Prices and Business Cycles with Costly External Finance. Review of Economic Dynamics 6(4), 767-788. https://doi.org/10.1016/S1094-2025(03)00061-9.

Hayashi, F. (1982). Tobin's Marginal q and Average q: A Neoclassical Interpretation. Econometrica 50(1), 213-224. http://doi.org/10.2307/1912538.

Jermann, U. J. (1998). Asset Pricing in Production Economies. Journal of Monetary Economics 41(2), 257-275. https://doi.org/10.1016/S0304-3932(97)00078-0.

Justiniano, A., G. E. Primiceri, and A. Tambalotti (2011). Investment Shocks and the Relative Price of Investment. Review of Economic Dynamics 14(1), 102-121. https://doi.org/10.1016/j.red.2010.08.004.

Kiyotaki, N. and J. Moore (1997). Credit Cycles. Journal of Political Economy 105(2), 211-248. https://doi.org/10.1086/262072.

Kocherlakota, N. R. (2000). Creating Business Cycles Through Credit Constraints. Federal Reserve Bank of Minneapolis Quarterly Review 24(3), 2-10. https://doi.org/10.21034/qr.2431.

Koop, G., M. H. Pesaran, and S. Potter (1996). Impulse Response Analysis in Nonlinear Multivariate Models. Journal of Econometrics $74(1), 119-147$. https://doi.org/10.1016/0304-4076(95)01753-4.

Levin, A. T., F. M. Natalucci, and E. Zakrajsek (2004). The Magnitude and Cyclical Behavior of Financial Market Frictions. Finance and Economics Discussion Series (FEDS) Working Paper No. 2004-70. Federal Reserve Board, Washington, D.C. https://doi.org/10.17016/feds.2004.70.

L'huissier, S. and F. Tripier (2019). Regime-Dependent Effects of Uncertainty Shocks: A Structural Interpretation. Banque de France Working Paper 714. https://doi.org/10.2139/ssrn.3354571.

Lombardo, G. and P. McAdam (2012). Financial Market Frictions in a Model of the Euro Area. Economic Modelling 29, 2460-2485. https://doi.org/10.1016/j.econmod.2012.06.024. 
Martínez-García, E. (2014). U.S. Business Cycles, Monetary Policy and the External Finance Premium. In F. Schleer-van Gellecom (Ed.), Advances in Non-Linear Economic Modeling: Theory and Applications, Volume 17 of Dynamic Modeling and Econometrics in Economics and Finance, Chapter 2, pp. 41-114. Berlin, Heidelberg: Spriger. https://doi.org/10.1007/978-3-642-42039-9_2.

Martínez-García, E. (2018). Modeling Time-Variation Over the Business Cycle (19602017): An International Perspective. Studies in Nonlinear Dynamics and Econometrics 22(5), 1-25. https://doi.org/10.1515/snde-2017-0101.

Mendicino, C. and Y. Zhang (2018). Risk Shocks in a Small Open Economy: Business Cycle Dynamics in Canada. Economic Modelling 72, 391-409. https://doi.org/10.1016/j.econmod.2018.02.014.

Oh, J. (2020). The Propagation of Uncertainty Shocks: Rotemberg Versus Calvo. International Economic Review 61(3), 1097-1113. https://doi.org/10.1111/iere.12450.

Paleka, J. and B. Schwanebeck (2017). Financial Frictions and Optimal Stabilization Policy in a Monetary Union. Economic Modelling 61, 462-477. https://doi.org/10.1016/j.econmod.2016.12.024.

Pindyck, R. S. (1988). Irreversible Investment, Capacity Choice, and the Valuation of the Firm. American Economic Review 78(5), 969-985. https://www.jstor.org/stable/1807160.

Rotemberg, J. J. (1982). Sticky Prices in the United States. Journal of Political Economy $90(6)$, 1187-1211. https://www.jstor.org/stable/1830944.

Smets, F. and R. Wouters (2007). Shocks and Frictions in U.S. Business Cycles: A Bayesian DSGE Approach. American Economic Review 97(3), 586-606. https://doi.org/10.1257/aer.97.3.586.

Swanson, E. T. (2018). Risk Aversion, Risk Premia, and the Labor Margin with Generalized Recursive Preferences. Review of Economic Dynamics 28, 290-321. https://doi.org/10.1016/j.red.2017.10.003.

Taylor, J. B. (1993). Discretion versus Policy Rules in Practice. Carnegie-Rochester Conference Series on Public Policy 39, 195-214. https://doi.org/10.1016/01672231(93)90009-1.

Townsend, R. M. (1979). Optimal Contracts and Competitive Markets with Costly State Verification. Journal of Economic Theory 21(2), 265-293. 
https://doi.org/10.1016/0022-0531(79)90031-0. 


\section{Appendix}

\subsection{Solution Strategy: Pruned Third-Order Approximation}

The equilibrium conditions that characterize the model solution can be compactly stated as:

$$
\mathbb{E}_{t} f\left(\mathbf{y}_{t+1}, \mathbf{y}_{t}, \mathbf{x}_{t+1}, \mathbf{x}_{t}, \mathbf{v}_{t+1}, \mathbf{v}_{t}\right)=0
$$

where $\mathbb{E}_{t}$ denotes the mathematical expectations operator conditional on information available at time $t, \mathbf{y}_{t}$ is a vector of $n_{y}$ control variables expressed in logs, $\mathbf{x}_{t}$ is a vector of $n_{x}$ state variables in logs, and the vector $v_{t}$ contains all $n_{v}$ structural shock innovations. The nonlinear equilibrium relationships of the model are represented with the functional operator $f(\cdot)$. The solution to (39) can be cast with the following measurement and state equations:

$$
\begin{aligned}
\mathbf{y}_{t} & =g\left(\mathbf{x}_{t}, \tau\right) \\
\mathbf{x}_{t+1} & =h\left(\mathbf{x}_{t}, \tau\right)+\tau \boldsymbol{\Sigma} \mathbf{v}_{t+1}
\end{aligned}
$$

where $\boldsymbol{\Sigma}$ is an $n_{x} \times n_{v}$ variance-covariance matrix of the shock innovations and $\tau$ is the perturbation parameter scaling it. We use a third-order approximation to functions $g(\cdot)$ and $h(\cdot)$ around the deterministic (zero-net inflation) steady state where $\mathbf{x}_{t}=\mathbf{x}$ and $\tau=0$.

The first, second, and third partial derivatives of $g(\cdot)$ and $h(\cdot)$ with respect to the components of $\mathbf{x}_{t}$ and the perturbation parameter $\tau$ are used to compute the pruned thirdorder approximation. Pruning eliminates terms of order higher than three from the impulse responses and other dynamic analysis as these higher order terms can lead to dynamic instability, as suggested by Andreasen et al. (2018). ${ }^{41}$ If the first-order approximation is stationary, then so are the pruned second- and third-order approximations. Here, the pruned

\footnotetext{
${ }^{41}$ We also investigated the unpruned third-order approximation, but the resulting impulse response functions and dynamics are almost indistinguishable from the pruned ones. We only find noticeable, but very tiny differences in the responses to monetary policy shocks. Those results are not included in the paper to economize on space.
} 
third-order approximation has the following form:

$$
\begin{aligned}
\mathbf{y}_{t}^{r d}= & g_{x}\left(\mathbf{x}_{t}^{f}+\mathbf{x}_{t}^{s}+\mathbf{x}_{t}^{r d}\right)+\frac{1}{2} G_{x x}\left(\left(\mathbf{x}_{t}^{f} \otimes \mathbf{x}_{t}^{f}\right)+2\left(\mathbf{x}_{t}^{f} \otimes \mathbf{x}_{t}^{s}\right)\right) \ldots \\
& +\frac{1}{6} G_{x x x}\left(\mathbf{x}_{t}^{f} \otimes \mathbf{x}_{t}^{f} \otimes \mathbf{x}_{t}^{f}\right)+\frac{1}{2} g_{\tau \tau} \tau^{2}+\frac{3}{6} g_{\tau \tau x} \tau^{2} \mathbf{x}_{t}^{f}+\frac{1}{6} g_{\tau \tau \tau} \tau^{3}, \\
\mathbf{x}_{t+1}^{f}= & h_{x} \mathbf{x}_{t}^{f}+\tau \Sigma \mathbf{v}_{t+1}, \\
\mathbf{x}_{t+1}^{s}= & h_{x} \mathbf{x}_{t}^{s}+\frac{1}{2} H_{x x}\left(\mathbf{x}_{t}^{f} \otimes \mathbf{x}_{t}^{f}\right)+\frac{1}{2} h_{\tau \tau} \tau^{2}, \\
\mathbf{x}_{t+1}^{r d}= & h_{x} \mathbf{x}_{t}^{r d}+H_{x x}\left(\mathbf{x}_{t}^{f} \otimes \mathbf{x}_{t}^{s}\right)+\frac{1}{6} H_{x x x}\left(\mathbf{x}_{t}^{f} \otimes \mathbf{x}_{t}^{f} \otimes \mathbf{x}_{t}^{f}\right)+\frac{3}{6} h_{\tau \tau x} \tau^{2} \mathbf{x}_{t}^{f}+\frac{1}{6} h_{\tau \tau \tau} \tau^{3},
\end{aligned}
$$

where $\mathbf{y}_{t}^{r d}$ are the pruned third-order approximations of the control variables, $\mathbf{x}_{t}^{f}$ are state variables based on the first-order approximation, $\mathbf{x}_{t}^{s}$ are the state variables second-order approximation terms, and $\mathbf{x}_{t}^{r d}$ are the state variables third-order terms. The first-order derivatives are: $g_{x}\left(n_{y} \times n_{x}\right.$ matrix $)$ and $h_{x}\left(n_{x} \times n_{x}\right.$ matrix $)$. The second-order derivatives are: $G_{x x}\left(n_{y} \times n_{x}^{2}\right.$ matrix $), H_{x x}\left(n_{x} \times n_{x}^{2}\right.$ matrix $), g_{\tau \tau}\left(n_{y} \times 1\right.$ vector $)$, and $h_{\tau \tau}\left(n_{x} \times 1\right.$ vector $)$. The third-order derivatives are: $G_{x x x}\left(n_{y} \times n_{x}^{3}\right.$ matrix $), H_{x x x}\left(n_{x} \times n_{x}^{3}\right.$ matrix $), g_{\tau \tau x}\left(n_{y} \times n_{x}\right.$ matrix), $h_{\tau \tau x}\left(n_{y} \times n_{x}\right.$ matrix $), g_{\tau \tau \tau}\left(n_{y} \times 1\right.$ vector $)$, and $h_{\tau \tau \tau}\left(n_{x} \times 1\right.$ vector $)$. We use Dynare to find the first-, second-, and third-order perturbation solutions and extract the matrices relevant to compute the pruned third-order approximation.

\subsection{Modeling Mean-Preserving Stochastic Volatility}

At a general level, uncertainty is defined as the conditional volatility (second-moment) of a disturbance that is unforecastable by economic agents and arises independently of economic

and policy shocks. We model second-moment shocks as mean-preserving stochastic volatility to prevent, in turn, those second-moments shocks from having first-order effects on the firstmoment economic and policy shocks under log-normality.

As discussed in greater detail in Balke et al. (2017b), in our model all shock processes with stochastic volatility - aggregate productivity (TFP), idiosyncratic productivity, and monetary policy shocks, i.e., $z_{t} \in\left\{a_{t}, \ln \left(\omega_{t}\right), m_{t}\right\}$ - can be cast in canonical form:

$$
\begin{aligned}
z_{t} & =\mu_{z, t}+\rho_{z}\left(z_{t-1}-\mu_{z, t-1}\right)+\sigma_{z} e^{\widehat{\sigma}_{z, t}} \varepsilon_{z, t}, \\
\mu_{z, t} & =-\frac{\left(\sigma_{z} e^{\widehat{\sigma}_{z, t}}\right)^{2}}{2}+\left(\rho_{z}\right)^{2} \mu_{z, t-1} \\
\widehat{\sigma}_{z, t} & =v_{z} \widehat{\sigma}_{z, t-1}+\eta_{z} u_{z, t}
\end{aligned}
$$


where $\widehat{\sigma}_{z, t}=\ln \sigma_{z, t}-\ln \sigma_{z}$ and $\sigma_{z, t} \equiv \sigma_{z} e^{\widehat{\sigma}_{z, t}}$. The innovation terms $\varepsilon_{z, t}$ and $u_{z, t}$ are i.i.d. $N(0,1)$ and uncorrelated. Differences between conditional and unconditional moments of the distribution can arise under this canonical form-hence, we must note that the notion of mean-preserving spread that we adopt in this paper is that of a mean-preserving spread conditional on the history of the volatility shocks.

Any shock $z_{t} \in\left\{a_{t}, \ln \left(\omega_{t}\right), m_{t}\right\}$ is specified in logs as a stochastic (Gaussian) process, but appears in the model equilibrium conditions in levels (as $e^{z_{t}}$ ). Under the assumption of log-normality, an increase in $\sigma_{z, t}$ increases not only the variance of the shock (the dispersion for $e^{z_{t}}$ ) but also the expected mean value of $e^{z_{t}}$. Since we are interested in mean-preserving spreads that arise solely because of shifts in the dispersion of the distribution and not from indirect effects coming through the mean, we introduce a recursive correction given in (47) that reverses the conditional mean-effect of volatility on the time-varying conditional mean of the shock process $\mu_{z, t}$.

To show that this recursive correction is conditional mean-preserving, note first that $z_{t}$ and $\mu_{z, t}$ can be expanded backwards as follows:

$$
\begin{aligned}
z_{t} & =\mu_{z, t}+\sum_{i=0}^{\infty}\left(\rho_{z}\right)^{i} \sigma_{z, t-i} \varepsilon_{z, t-i} \\
\mu_{z, t} & =-\sum_{i=0}^{\infty}\left(\rho_{z}^{2}\right)^{i} \frac{\sigma_{z, t-i}^{2}}{2}
\end{aligned}
$$

When we compute the mean of the process $e^{z_{t}}$ conditional on the history of the volatility shocks, we obtain the following expression under the time-varying conditional mean $\left(\mu_{z, t}\right)$ recursion given in (47):

$$
\begin{aligned}
\mathbb{E} & {\left[e^{z_{t}} \mid \sigma_{z, t-i}, i=0, \ldots, \infty\right] } \\
& =\mathbb{E}\left[e^{\mu_{z, t}+\sum_{i=0}^{\infty}\left(\rho_{z}\right)^{i} \sigma_{z, t-i} \varepsilon_{z, t-i}} \mid \sigma_{z, t-i}, i=0, \ldots, \infty\right] \\
& =e^{\left(-\sum_{i=0}^{\infty}\left(\rho_{z}^{2}\right)^{i} \frac{\sigma_{z, t-i}^{2}}{2}\right)} \mathbb{E}\left[e^{\left(\sum_{i=0}^{\infty}\left(\rho_{z}\right)^{i} \sigma_{z, t-i} \varepsilon_{z, t-i}\right)} \mid \sigma_{z, t-i}, i=0, \ldots, \infty\right] \\
& \left.=e^{\left(-\sum_{i=0}^{\infty}\left(\rho_{z}^{2}\right)^{i} \frac{\sigma_{z, t-i}^{2}}{2}\right)} e^{\mathbb{E}\left(\sum_{i=0}^{\infty}\left(\rho_{z}\right)^{i} \sigma_{z, t-i} \varepsilon_{z, t-i} \mid \sigma_{z, t-i}, i=0, \ldots, \infty\right)+\frac{1}{2} \mathbb{V}\left(\sum_{i=0}^{\infty}\left(\rho_{z}\right)^{i} \sigma_{z, t-i} \varepsilon_{z, t-i} \mid \sigma_{z, t-i}, i=0, \ldots, \infty\right)}\right) \\
& =e^{\left(-\sum_{i=0}^{\infty}\left(\rho_{z}^{2}\right)^{i \frac{\sigma_{z, t-i}^{2}}{2}}\right)} e^{\left(\sum_{i=0}^{\infty}\left(\rho_{z}^{2}\right)^{i \frac{\sigma_{z, t-i}^{2}}{2}}\right)}=1,
\end{aligned}
$$

which follows given that $\varepsilon_{z, t}$ are i.i.d. $N(0,1)$ innovations. As a result, this shows that the 
recursive correction proposed in (47) ensures that the conditional mean of the shock $z_{t}$ in levels is not affected by a change in the second moment $\sigma_{z, t}$. This is the sense in which the specification of the stochastic volatility shocks is said to be mean-preserving in our model.

Finally, we consider the implications that this mean-preserving correction has on the steady state. The standard way we characterize the deterministic steady state is: (a) to assume that $\varepsilon_{z, t}$ and $u_{z, t}$ are replaced by their unconditional means (i.e., replaced by $\mathbb{E}\left(\varepsilon_{z, t}\right)=$ $\mathbb{E}\left(u_{z, t}\right)=0$ ), and (b) to drop the time subscript in the corresponding dynamic equations in the canonical form. Based on that logic, we get the following set of equations for the deterministic steady state:

$$
\begin{aligned}
z & =\mu_{z}=-\frac{1}{2} \frac{\sigma_{z}^{2}}{1-\rho_{z}^{2}}, \\
\widehat{\sigma}_{z} & =0
\end{aligned}
$$

for each $z \in\{a, \ln (\omega), m\}$. This describes the steady state for all shocks $z$ under our conditional mean-preserving recursive correction. 